\title{
Complement Protein C1q Interacts with DC-SIGN via Its Globular Domain and Thus May Interfere with HIV-1 Transmission
}

\author{
Lina Pednekar', Hrishikesh Pandit², Basudev Paudyal', Anuvinder Kaur', \\ Maha Ahmed Al-Mozaini', Lubna Kouser ${ }^{1}$, Berhane Ghebrehiwet ${ }^{4}$, Daniel A. Mitchell'5, \\ Taruna Madan ${ }^{2}$ and Uday Kishore ${ }^{1 *}$
}

\begin{abstract}
${ }^{1}$ Biosciences, College of Health and Life Sciences, Brunel University London, Uxbridge, UK, ${ }^{2}$ Department of Innate Immunity, National Institute for Research in Reproductive Health (ICMR), Mumbai, India, ${ }^{3}$ Department of Infection and Immunity, King Faisal Specialist Hospital and Research Centre, Riyadh, Saudi Arabia, ${ }^{4}$ Department of Medicine, State University of New York, Stony Brook, NY, USA, ${ }^{5}$ Clinical Sciences Research Laboratories, University of Warwick, Coventry, UK
\end{abstract}

\section{OPEN ACCESS}

Edited by:

Cees Van Kooten,

Leiden University, Netherlands

Reviewed by:

Kenneth Reid,

Green Templeton College

University of Oxford, UK

Lubka T. Roumenina,

INSERM UMRS 1138, Cordeliers

Research Center, Complement and

Diseases Team, France

*Correspondence:

Uday Kishore

uday.kishore@brunel.ac.uk,

ukishore@hotmail.com

Specialty section:

This article was submitted to

Molecular Innate Immunity,

a section of the journal

Frontiers in Immunology

Received: 06 August 2016 Accepted: 30 November 2016 Published: 22 December 2016

Citation:

Pednekar L, Pandit H, Paudyal B, Kaur A, Al-Mozaini MA, Kouser L,

Ghebrehiwet B, Mitchell DA,

Madan T and Kishore U (2016) Complement Protein C1q Interacts

with DC-SIGN via Its Globular

Domain and Thus May Interfere with HIV-1 Transmission.

Front. Immunol. 7:600.

doi: 10.3389/fimmu.2016.00600
Dendritic cells (DCs) are the most potent antigen-presenting cells capable of priming naiive T-cells. Its C-type lectin receptor, DC-SIGN, regulates a wide range of immune functions. Along with its role in HIV-1 pathogenesis through complement opsonization of the virus, DC-SIGN has recently emerged as an adaptor for complement protein C1q on the surface of immature DCs via a trimeric complex involving $\mathrm{gC} 1 \mathrm{qR}$, a receptor for the globular domain of $\mathrm{C} 1 \mathrm{q}$. Here, we have examined the nature of interaction between C1q and DC-SIGN in terms of domain localization, and implications of C1qDC-SIGN-gC1qR complex formation on HIV-1 transmission. We first expressed and purified recombinant extracellular domains of DC-SIGN and its homologue DC-SIGNR as tetramers comprising of the entire extra cellular domain including the $\alpha$-helical neck region and monomers comprising of the carbohydrate recognition domain only. Direct binding studies revealed that both DC-SIGN and DC-SIGNR were able to bind independently to the recombinant globular head modules ghA, ghB, and ghC, with ghB being the preferential binder. C1q appeared to interact with DC-SIGN or DC-SIGNR in a manner similar to lgG. Mutational analysis using single amino acid substitutions within the globular head modules showed that $\mathrm{Tyr}^{\mathrm{B175}}$ and $\mathrm{Lys}^{\mathrm{B} 136}$ were critical for the C1q-DC-SIGN/DC-SIGNR interaction. Competitive studies revealed that $\mathrm{gC} 1 \mathrm{qR}$ and ghB shared overlapping binding sites on DC-SIGN, implying that HIV-1 transmission by DCs could be modulated due to the interplay of gC1qR-C1q with DC-SIGN. Since C1q, gC1qR, and DC-SIGN can individually bind HIV-1, we examined how C1q and gC1qR modulated HIV-1-DC-SIGN interaction in an infection assay. Here, we report, for the first time, that C1q suppressed DC-SIGN-mediated transfer of HIV-1 to activated pooled peripheral blood mononuclear cells, although the globular head modules did not. The protective effect of $\mathrm{C} 1 \mathrm{q}$ was negated by the addition of $\mathrm{gC} 1 \mathrm{qR}$. In fact, gC1qR enhanced DC-SIGN-mediated HIV-1 transfer, suggesting its role in HIV-1 pathogenesis. Our results highlight the consequences of multiple innate immune pattern recognition molecules forming a complex that can modify their functions in a way, which may be advantageous for the pathogen.

Keywords: DC-SIGN, C1q, globular head domain, HIV-1, protein-protein interaction 


\section{INTRODUCTION}

Dendritic cell-specific intracellular adhesion grabbing nonintegrin (DC-SIGN) is a C-type lectin expressed on DCs that functions as a pattern recognition receptor (PRR). It can interact with a range of viral, bacterial, and fungal pathogens to primarily promote Th2 responses via activation of the mitogen-activated protein kinases Erk1 and Erk2 (1), leading to the clearance of pathogens. DC-SIGN also modulates TLR signalling by activating serine and threonine kinase Rafl, which acetylates the NF- $\mathrm{KB}$ subunit $\mathrm{p} 65$ upon interaction with pathogens, such as Mycobacterium tuberculosis, Mycobacterium leprae, Candida albicans, and measles virus $(2,3)$. Acetylation of p65 and increased IL-10 transcription leads to an enhanced anti-inflammatory cytokine response (2). DC-SIGN also mediates DC-T cell interaction via intracellular adhesion molecule-3 (ICAM-3) (4). In addition, DCs can adhere to endothelial cells expressing high levels of ICAM-2 via DC-SIGN. Further interactions between lymphocyte function-associated antigen-1 (LFA-1) and ICAM-1 with ICAM-2-DC-SIGN (5) promote trans-endothelial migration of DCs, allowing them to travel from the blood to the lymphatic system where they can induce T cell responses. Martinez et al. have shown that DC-SIGN stimulated CD3-activated T cells produce IL-2, which, in turn, enhances $\mathrm{T}$ cell differentiation (6). DC-SIGN can bind the cell wall component, glycolipid ManLAM of $M$. tuberculosis, and inhibit DC maturation through the suppression of TLR-4 (7). Such a cross talk between TLRs and DC-SIGN that generates anti-inflammatory immune response highlights the two-faced role of DC-SIGN in immune regulation.

DC-SIGN can bind to HIV-1 envelope protein gp120 through glycan structures (8) and mediate HIV transmission in cis and trans fashion. The cis mode supports DC-SIGN-mediated viral internalization and limited replication; in trans mode, viral particles are endocytosed and presented to $\mathrm{CD}^{+}$cells (9). DC-SIGN, thus, allows DCs to carry HIV-1 to the lymph nodes where interactions between DCs and T cells leads to transmission of the virus to $\mathrm{CD} 4^{+} \mathrm{T}$ cells, leading to their infection and eventual depletion (10). The hepatitis C virus (HCV) envelope glycoprotein E2 is another viral protein DC-SIGN engages with (11). This is achieved through utilizing its high quality endocytic capability to internalize the viral antigen, leading to the infection of DCs (12).

Structurally, DC-SIGN is composed of an extracellular domain (ECD), which exists as a tetramer, stabilized by an $\mathrm{N}$-terminal $\alpha$-helical neck region, followed by a carbohydrate recognition domain (CRD) (8). Its affinity for N-linked high mannose oligosaccharides is evident through its ligands HIV-1 gp120 and ICAM-3 being highly glycosylated, indicating that this binding is mediated through the CRD region $(13,14)$. Studies have shown that the interaction between gp 120 and DC-SIGN triggers a drop in IL-6 production by immature DCs. In addition, gp 120 binding to DC-SIGN has also been shown to suppress the anti-apoptotic activity of Nef and induce apoptosis in immature DCs (14). Thus, HIV pathogenesis heavily relies on the interplay of molecular mechanisms involving DC-SIGN.

Recently, it has emerged that DC-SIGN interacts with the complement classical pathway recognition protein, $\mathrm{C1q}$ (15), in conjunction with its globular head receptor, $\mathrm{gClqR}$, on the surface of immature DCs. C1q as well as $\mathrm{gCl} \mathrm{qR}$ is known to associate with the viral envelope protein gp41 of HIV-1 $(16,17)$. C1q has been shown to interact with gp41 ectodomain via its globular head ( $\mathrm{gClq}$ ) domain (18), specifically via the A chain (19), in a way similar to $\mathrm{C} 1 \mathrm{q}-\operatorname{IgG}$ interaction $(20,21)$. Similar to $\operatorname{IgG}$, the ability of gp41 to form aggregates (16) leads to an enhanced activation of the $\mathrm{C} 1$ complex, as well as the function of gp41 to initiate the classical pathway on the surface of infected cells in an antibody-independent manner (22). The C1q binding site on gp41 resides within residues $601-613$ of the immunodominant loop region (16), which contains hydrophobic side chains and forms a cleft (23).

$\mathrm{gClqR}$ on its own has been shown to suppress the production of HIV-1 in MT-4 and H9 human T cell lines, and macrophages infected with HIV-1 $1_{\text {IIIB }}$ and HIV-1 $1_{\mathrm{Ba}-\mathrm{L}}$ (24) Suppression of virus production is further enhanced when $\mathrm{gClqR}$ is preincubated with the target cell lines prior to HIV-1 challenge, suggesting that interference with viral entry by $\mathrm{gClqR}$ occurs through interaction with $\mathrm{CD} 4$ (24). $\mathrm{gClqR}$ is known to bind to a range of viral ligands including the HCV core protein (25), adenovirus core protein V (26) EBNA-1 (27), and rubella virus capsid protein (28). gC1qR can also act as a receptor for HIV-1 gp41 and target healthy $\mathrm{CD} 4^{+} \mathrm{T}$ cells to natural killer (NK) cell-mediated lysis (17). This bystander effect of autologous killing occurs through the surface translocation of NKP44L, via activation of PI3K, NADPH oxidase, and p190 RhoGAP.

Recently, DC-SIGN, C1q, and gC1qR on immature DCs have been shown to form a tripartite complex, with a plausible role in DC differentiation through signaling via the NF- $\mathrm{KB}$ pathway (15). Given that each of these innate immune proteins (Clq, DC-SIGN, and gC1qR) can bind HIV-1, we set out to dissect the nature of interaction between C1q and DC-SIGN and examine how it can impact upon HIV-1 transmission.

\section{MATERIALS AND METHODS}

\section{Expression and Purification of Soluble DC-SIGN and DC-SIGNR}

The pT5T constructs expressing tetrameric and monomeric forms of DC-SIGN and DC-SIGNR were transformed into Escherichia coli BL21 ( $\lambda$ DE3) (8). Protein expression was performed using bacterial culture in Luria-Bertani medium containing $50 \mu \mathrm{g} / \mathrm{mL}$ of ampicillin at $37^{\circ} \mathrm{C}$ until $\mathrm{OD}_{600}$ reached 0.7 . The bacterial culture was induced with $10 \mathrm{mM}$ isopropyl$\beta$-D-thiogalactoside (IPTG) and incubated for a further $3 \mathrm{~h}$. Bacterial cells $(1 \mathrm{~L})$ were centrifuged at $4,500 \times g$ for $15 \mathrm{~min}$ at $4^{\circ} \mathrm{C}$ and cell pellet was treated with $22 \mathrm{~mL}$ of lysis buffer containing $100 \mathrm{mM}$ Tris, pH 7.5, $0.5 \mathrm{M} \mathrm{NaCl}$, lysozyme (50 $\mu \mathrm{g} /$ $\mathrm{mL}$ ), $2.5 \mathrm{mM}$ EDTA, pH 8.0, and $0.5 \mathrm{mM}$ phenylmethylsulfonyl fluoride (PMSF), and left to stir for $1 \mathrm{~h}$ at $4^{\circ} \mathrm{C}$. Cells were then sonicated for 10 cycles for $30 \mathrm{~s}$ with 2 min intervals and the sonicated suspension was spun at $10,000 \mathrm{~g}$ for $15 \mathrm{~min}$ at $4^{\circ} \mathrm{C}$. The inclusion bodies, present in the pellet, were solubilized in $20 \mathrm{~mL}$ of $6 \mathrm{M}$ urea, $10 \mathrm{mM}$ Tris- $\mathrm{HCl}, \mathrm{pH} 7.0$, and $0.01 \%$ $\beta$-mercaptoethanol by rotating on a shaker for $1 \mathrm{~h}$ at $4^{\circ} \mathrm{C}$. 
The mixture was then centrifuged at $13,000 \times g$ for $30 \mathrm{~min}$ at $4^{\circ} \mathrm{C}$, and the supernatant was drop-wise diluted fivefold with loading buffer containing $25 \mathrm{mM}$ Tris- $\mathrm{HCl} \mathrm{pH} 7.8,1 \mathrm{M} \mathrm{NaCl}$, and $2.5 \mathrm{mM} \mathrm{CaCl}_{2}$ with gentle stirring. This was then dialyzed against $2 \mathrm{~L}$ of loading buffer with three buffer changes every $3 \mathrm{~h}$. Following further centrifugation at $13,000 \times g$ for $15 \mathrm{~min}$ at $4^{\circ} \mathrm{C}$, the supernatant was loaded onto a mannan-agarose column (5 mL; Sigma) pre-equilibrated with the loading buffer. The column was washed with five bed volumes of the loading buffer, and the bound protein was eluted in $1 \mathrm{~mL}$ fractions using the elution buffer containing $25 \mathrm{mM}$ Tris- $\mathrm{HCl}$ pH 7.8, $1 \mathrm{M} \mathrm{NaCl}$, and $2.5 \mathrm{mM}$ EDTA. The absorbance was read at $280 \mathrm{~nm}$, and the peak fractions were frozen at $-20^{\circ} \mathrm{C}$. Purity of protein was analyzed by $15 \% \mathrm{w} / \mathrm{v}$ SDS-PAGE.

\section{Expression and Purification of Recombinant Wild-Type Globular Head Modules ghA, ghB, and ghC of Human C1q and Their Substitution Mutants}

The recombinant globular head regions of human $\mathrm{C} 1 \mathrm{q}$, ghA, ghB, and ghC modules (19) and their respective mutants (29) were expressed in E. coli BL21 as fusion to maltose-binding protein (MBP). Bacterial cells were grown in $200 \mathrm{~mL} \mathrm{LB}$ medium containing ampicillin $(100 \mu \mathrm{g} / \mathrm{mL})$ at $37^{\circ} \mathrm{C}$, and induced with $0.4 \mathrm{mM}$ IPTG at $\mathrm{OD}_{600}$ of 0.6 for $3 \mathrm{~h}$, and then centrifuged $(4,500 \times g$ for $15 \mathrm{~min})$. The cell pellet was suspended in $25 \mathrm{~mL}$ of lysis buffer (20 mM Tris-HCl pH 8.0, 0.5 M NaCl, 1 mM EDTA, $0.2 \% \mathrm{v} / \mathrm{v}$ Tween 20,5\% glycerol, $0.1 \mathrm{mM}$ PMSF, and $0.1 \mathrm{mg}$ lysozyme) and incubated at $4^{\circ} \mathrm{C}$ for $1 \mathrm{~h}$ on a rotary shaker. Cell suspension was then sonicated for $30 \mathrm{~s}$ with 2 min gaps for 10 cycles. After centrifugation $(13,000 \times g$ for $15 \mathrm{~min})$, the supernatant was diluted fivefold in buffer I ( $20 \mathrm{mM}$ Tris- $\mathrm{HCl}, \mathrm{pH} 8.0$, $100 \mathrm{mM} \mathrm{NaCl}, 0.2 \%$ Tween 20, 1 mM EDTA, and 5\% glycerol), passed through an amylose resin column $(15 \mathrm{~mL}$; New England Biolabs), and then washed with three bed volumes of buffer I followed by buffer II ( $50 \mathrm{~mL}$ of buffer I without Tween 20). The protein was then eluted in $1 \mathrm{~mL}$ fractions with $10 \mathrm{mM}$ maltose in $100 \mathrm{~mL}$ of buffer II and frozen at $-20^{\circ} \mathrm{C}$ after determining protein concentration and purity via Nanodrop and $10 \% \mathrm{w} / \mathrm{v}$ SDS-PAGE, respectively.

\section{Purification of Human C1q from Plasma}

C1q was purified from freshly thawed plasma as described previously (19). Briefly, plasma was made 5 mM EDTA, pH 7.5, and centrifuged to remove aggregated lipids. It was then incubated with non-immune IgG coupled to $\mathrm{CNBr}$-activated Sepharose (GE Healthcare, UK) for $1 \mathrm{~h}$ at $4^{\circ} \mathrm{C}$. The plasma with IgG-Sepharose was filtered through a sintered glass funnel, and C1q-bound Sepharose was then washed extensively with $10 \mathrm{mM}$ HEPES, $140 \mathrm{mM} \mathrm{NaCl}, 0.5 \mathrm{mM}$ EDTA, pH 7.0. C1q was eluted with CAPS (N-cyclohexyl-3-aminopropanesulfonic acid) buffer $(100 \mathrm{mM}$ CAPS, $1 \mathrm{M} \mathrm{NaCl}, 0.5 \mathrm{mM}$ EDTA, pH 11). The eluted C1q was then passed through a HiTrap protein G column (PierceNet, USA) to remove IgG contaminants and dialyzed against the washing buffer.

\section{Expression and Purification of Human gC1qR}

The recombinant mature $\mathrm{gClqR}$ protein containing 74-282 residues was expressed in E. coli BL21 ( $\lambda$ DE3) (30). Bacterial cells were grown in $250 \mathrm{~mL}$ of $\mathrm{LB}$ at $37^{\circ} \mathrm{C}$ until an $\mathrm{OD}_{600}$ of 0.6 was reached and induced with $0.5 \mathrm{mM}$ IPTG. After $3 \mathrm{~h}$, the bacterial cell culture was spun down $(4,500 \mathrm{~g}$ for $15 \mathrm{~min})$. The cell pellet was treated with lysis buffer $(20 \mathrm{mM}$ Tris- $\mathrm{HCl}$ pH 8.0, $0.5 \mathrm{M}$ $\mathrm{NaCl}, 1 \mathrm{mM}$ EDTA, $0.2 \%$ Tween, 5\% glycerol, $0.1 \mathrm{mg}$ lysozyme) and incubated for $1 \mathrm{~h}$ at $4^{\circ} \mathrm{C}$ with shaking. The cell lysate was then sonicated for 10 cycles at $30 \mathrm{~s}$ with 2 min intervals. The lysate was spun down at 13,000 $\mathrm{g}$ for $15 \mathrm{~min}$, and the supernatant was collected and dialyzed for $2 \mathrm{~h}$ against $20 \mathrm{mM}$ Tris- $\mathrm{HCl}, \mathrm{pH}$ 7.5. The dialyzed protein was subjected to ion exchange using a DEAE column and gC1qR eluted at a peak of $0.45 \mathrm{M} \mathrm{NaCl}$.

\section{Direct Binding ELISA}

Microtiter wells were coated overnight at $4^{\circ} \mathrm{C}$ with DC-SIGN or $\operatorname{DC}-\operatorname{SIGNR}(5,2.5,1.25$, and $0.625 \mu \mathrm{g} /$ well $)$ in carbonate-bicarbonate buffer, $\mathrm{pH} 9.6$, and left overnight at $4^{\circ} \mathrm{C}$. Wells were blocked with $100 \mu \mathrm{L}$ of $2 \% \mathrm{w} / \mathrm{v}$ BSA in PBS for $2 \mathrm{~h}$ at $37^{\circ} \mathrm{C}$. Following three washes with PBS $+0.05 \%$ Tween 20 , ghA, ghB, ghC, or its substitution mutants $(2.5 \mu \mathrm{g} / 100 \mu \mathrm{l})$ was added to each well in the buffer containing $50 \mathrm{mM} \mathrm{NaCl}, 100 \mathrm{mM}$ Tris- $\mathrm{HCl}, \mathrm{pH}$ 7.5, and $5 \mathrm{mM}$ $\mathrm{CaCl}_{2}$. MBP (Sigma) was used as a negative control. The plate was incubated at $37^{\circ} \mathrm{C}$ for $1.5 \mathrm{~h}$ and then at $4^{\circ} \mathrm{C}$ for $1.5 \mathrm{~h}$. The wells were washed and the bound protein was detected with anti-MBP monoclonal antibodies in PBS (1:5,000, Sigma) followed by rabbit anti-mouse IgG-HRP conjugate (1:5,000; Sigma) for $1 \mathrm{~h}$. The color was developed using o-phenylenediamine dihydrochloride (OPD, Sigma) and read at $415 \mathrm{~nm}$.

\section{Competitive ELISA}

DC-SIGN and DC-SIGNR proteins were coated on microtiter wells by overnight incubation at $4^{\circ} \mathrm{C}$ using $5 \mu \mathrm{g} /$ well (in $100 \mu \mathrm{L}$ ) in carbonate-bicarbonate buffer $\mathrm{pH}$ 9.6. Wells were blocked with $2 \% \mathrm{BSA}$ in $\mathrm{PBS}$ for $2 \mathrm{~h}$ at $37^{\circ} \mathrm{C}$. Following washing with PBS $+0.05 \%$ Tween, the plate was incubated with a steady concentration $(5 \mu \mathrm{g} /$ well) of one competing protein (gC1qR) and various concentrations $(5,2.5,1.25,0.625 \mu \mathrm{g} /$ well $)$ of the second competing protein $(\mathrm{ghB})$ in calcium buffer to give a total of $100 \mu \mathrm{L} /$ well. After incubating for $1.5 \mathrm{~h}$ at $37^{\circ} \mathrm{C}$ and $1.5 \mathrm{~h}$ at $4^{\circ} \mathrm{C}$, the wells were washed and anti-gC1qR polyclonal antibody $(1: 1,000)$ in PBS was added and incubated for a further $1 \mathrm{~h}$ at $37^{\circ} \mathrm{C}$. Bound protein was detected by Protein A-HRP conjugate $(1: 5,000)$, and the color was developed using OPD. Data were plotted to determine inhibition values of competitive ligand binding.

In order to examine if $\mathrm{C} 1 \mathrm{q}$ and globular head modules can inhibit binding of DC-SIGN to gp120, microtiter wells were coated with $250 \mathrm{ng}$ of gp120 (Abcam) in carbonate-bicarbonate buffer and left overnight at $4^{\circ} \mathrm{C}$. Plate was blocked with $2 \% \mathrm{w} / \mathrm{v}$ BSA in PBS for $2 \mathrm{~h}$ at $37^{\circ} \mathrm{C}$, followed by washing three times with $\mathrm{PBS}+0.05 \%$ Tween 20 . Various concentration of ghA, ghB, ghC, and $\mathrm{C} 1 \mathrm{q}(10,5,2.5,0 \mu \mathrm{g} / \mathrm{mL})$ were co-mixed with $2.5 \mu \mathrm{g} / \mathrm{mL}$ of DC-SIGN and added to wells in calcium buffer 
(100 $\mu \mathrm{L} /$ well). After incubation for $1 \mathrm{~h}$ at $37^{\circ} \mathrm{C}$ and $1 \mathrm{~h}$ at $4^{\circ} \mathrm{C}$, the wells were washed again three times using PBS $+0.05 \%$ Tween 20. The binding of DC-SIGN to gp120 in the presence of globular heads and C1q was detected using rabbit anti-DC-SIGN antibody (1:500) and probed with Protein A-HRP conjugate (1:5,000). The color was developed using 3,3',5,5' -tetramethylbenzidine (TMB) and read at $450 \mathrm{~nm}$ spectrophotometrically.

\section{Western Blotting}

Recombinant ghA, ghB, and ghC modules $(15 \mu \mathrm{g})$, in addition to $\mathrm{MBP}$ and $\mathrm{BSA}$ as negative control proteins, were run separately on a $12 \%$ SDS-PAGE gel and transferred onto PDVF membrane for $1 \mathrm{~h}$ at $320 \mathrm{~mA}$. Membrane was blocked in 5\% non-fat milk ( $1 \mathrm{~h}$ at room temperature) and $50 \mu \mathrm{g}$ of recombinant DC-SIGN (tetramer) in loading buffer (25 mM Tris- $\mathrm{HCl}, \mathrm{pH} 7.8,1 \mathrm{M} \mathrm{NaCl}$, $2.5 \mathrm{mM} \mathrm{CaCl}_{2}$ ) was added and incubated overnight at room temperature. The blot was washed three times for $10 \mathrm{~min}$ each in PBS containing $0.05 \%$ Tween 20 and then incubated with antiDC-SIGN $(1: 1,000)$ polyclonal antibody (ProSci) in $1 \%$ non-fat milk $\left(2 \mathrm{~h}\right.$ at $\left.37^{\circ} \mathrm{C}\right)$. Following subsequent washes, the membrane was incubated with Protein A-conjugated HRP $(1: 1,000)(1 \mathrm{~h}$ at room temperature). The blot was developed using 3, 3'-diaminobenzidine (DAB; Sigma D7679) as a substrate.

\section{Fluorescent Microscopy Binding of C1q Globular Head Modules to DC-SIGN Expressed on HEK Cells}

DC-SIGN-expressing HEK 293 (DC-HEK) cells, as reported by Lang et al. (31) were grown in DMEM-F12 (Life Technologies, UK) containing 10\% v/v FCS and blasticidin ( $5 \mu \mathrm{g} / \mathrm{mL})$ (Gibco). The cells were grown on $13 \mathrm{~mm}$ glass cover slips till a monolayer of cells was formed and then incubated with $15 \mu \mathrm{g} / \mathrm{mL}$ of recombinant ghA, ghB, and ghC ( $\mathrm{MBP}$ as a negative control) separately in serum free medium and left to incubate for $30 \mathrm{~min}$ in $37^{\circ} \mathrm{C}$. Cells were washed with PBS and fixed using $4 \% \mathrm{v} / \mathrm{v}$ paraformaldehyde for $10 \mathrm{~min}$, rinsed again with PBS three times, and then blocked with $5 \%$ FCS for $30 \mathrm{~min}$. The slides were incubated for 30 min with mouse anti-MBP antibody to detect MBP fusion proteins and rabbit anti-DC-SIGN antibody to reveal expression of DC-SIGN in DC-HEK cells. After three washes for $30 \mathrm{~min}$ each and incubation with secondary antibodies: Alexa Fluor 568 conjugated goat anti-mouse antibody (Thermo Fisher) and Alexa Fluor 488 conjugated goat anti-rabbit antibody (Abcam) for $30 \mathrm{~min}$, the slides were then washed in PBS, mounted, and observed under Leica DM4000 Fluorescent microscope using Leica Application Suite.

\section{HIV-1 Transfer Assay with DC-HEK Cells and Pooled Peripheral Blood Mononuclear Cell (PBMC)}

Pooled peripheral blood mononuclear cells (HiMedia Laboratories, India) were cultured in RPMI 1640 medium (Sigma Aldrich) containing 10\% FBS, 1\% Penicillin-Streptomycin (Complete RPMI medium), and stimulated with $5 \mu \mathrm{g} / \mathrm{mL}$ phytohemaglutinin (PHA) and $10 \mathrm{U} / \mathrm{Ml}$ of recombinant-human IL-2 (Gibco) for 24 h. PHA/IL-2 was washed off and activated PBMCs were cultured further for 3 days in complete RPMI 1640 medium.
DC-HEK cells were grown and maintained in DMEM-F12 (Sigma-Aldrich, USA) containing 10\% FBS and blasticidin $(5 \mu \mathrm{g} /$ $\mathrm{mL}$ ) (Gibco). Cells were sub-cultured every 3 days and those in the log phase were used for assays. DC-HEK cells were grown in a 12 well plate until $80 \%$ confluence. Indicated concentrations of C1q, ghA, ghB, ghC, and gC1qR individually, or in combination, in medium containing $5 \mathrm{mM} \mathrm{CaCl}_{2}$ were added to each well and incubated for $2 \mathrm{~h}$ to allow binding. Excess protein was removed and cells were challenged with $5 \mathrm{ng} / \mathrm{mL}$ p24 of HIV-1 SF-162 strain (kindly provided by Dr. Jay Levy, NIH AIDS Program, National Institutes of Health, USA) for $1 \mathrm{~h}$. MBP was added along with the virus as a negative protein control. Unbound virus was washed off and cells were co-cultured with PHA/IL-2 activated PBMCs for $24 \mathrm{~h}$ to facilitate viral transfer. PBMCs in the supernatant were then separated from the adhered DC-HEK monolayer and cultured further for 7 days and viral titer was determined using HIV-1 p24 antigen ELISA of supernatants collected on days 4 and 7 (XpressBio Life Science Products, Frederick, MD, USA). That the reduction in p24 levels was not due to cellular death was confirmed by MTT assay of cultured PBMCs on day 7.

\section{Statistical Analysis}

Viral transfer experiment data were plotted using GraphPad Prism version 5.0, and analyzed for statistical significance using one-way ANOVA. $P<0.05$ was considered as statistically significant.

\section{RESULTS}

\section{Both DC-SIGN and DC-SIGNR Bind to C1q}

DC-SIGN and DC-SIGNR comprising of the entire ECD (Figures 1A,C) and the CRD region alone (Figures 1B,D) were expressed in E. coli and affinity-purified on mannose-agarose. The CRD regions of DC-SIGN and DC-SIGNR bound mannose weakly as majority of the proteins appeared in the flow through. The ECD domains of both DC-SIGN and DC-SIGNR bound to mannose with much greater affinity in the presence of $\mathrm{Ca}^{2+}$ and eluted with EDTA. Previously, Kang et al. have shown that DC-SIGNR interacts with C1q (32). Recently, work by Hosszu et al. revealed that DC-SIGN bound directly to C1q (15). Thus, we examined direct binding of both the tetrameric and monomeric variants of DC-SIGN and DC-SIGNR with purified human C1q on microtiter plates. Both DC-SIGN (Figure 2A) and DC-SIGNR (Figure 3A) in their tetrameric and monomeric forms were able to bind to $\mathrm{Clq}$ in a dose-dependent manner. Experiment showed a strong binding of the tetramers to $\mathrm{C} 1 \mathrm{q}$ when compared to the $\mathrm{CRD}$ region alone, with the ability of $\mathrm{C} 1 \mathrm{q}$ to bind nearly $50 \%$ more when the $\alpha$-helical neck was intact. C1q bound to DC-SIGNR (Figure 3A) better than DC-SIGN (Figure 2A). The ability of the globular head modules to bind DC-SIGN was also examined via a far-western blot (Figure 2D), where ghA, ghB, and ghC, run on a SDS-PAGE and transferred on a nitrocellulose membrane, were probed with soluble DC-SIGN tetramer. ghA and ghB appeared to bind DC-SIGN well compared to the ghC module. MBP and BSA, used as negative control proteins, did not bind DC-SIGN tetramer. 


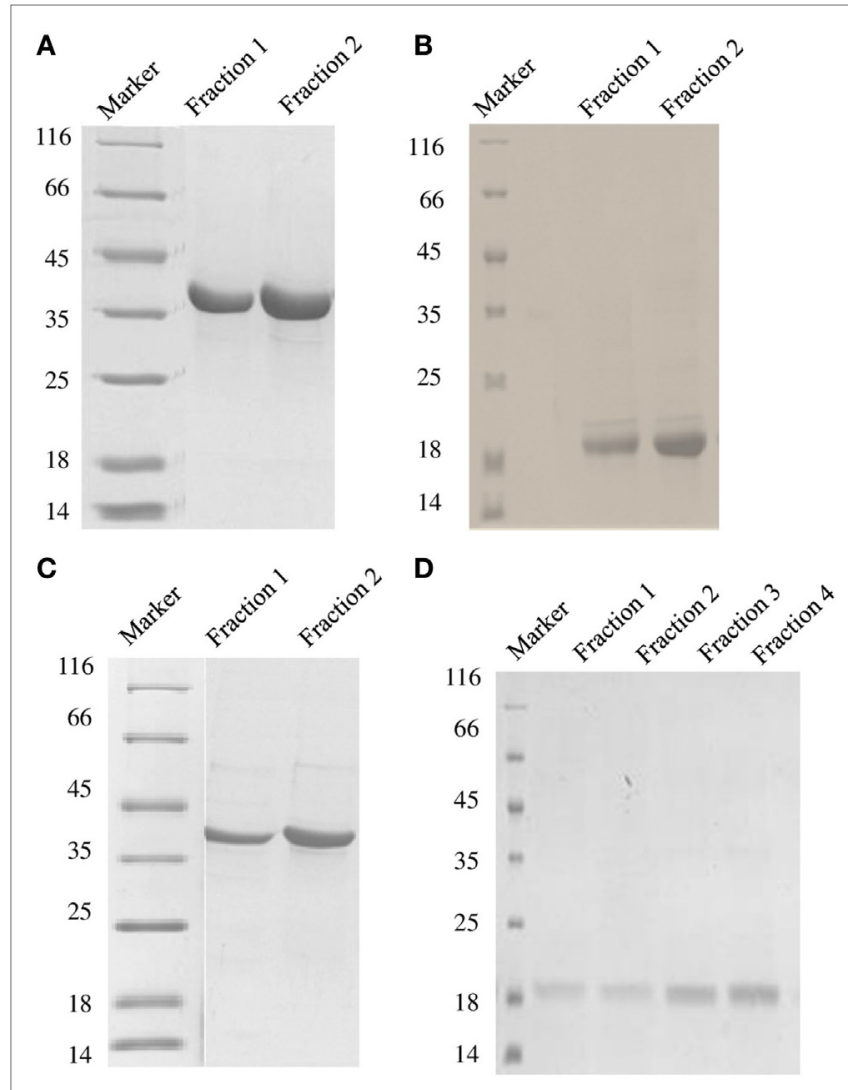

FIGURE 1 | SDS-PAGE under reducing conditions (12\% v/v) showing purified fractions of soluble DC-SIGN tetramer (A), DC-SIGN monomer (B), DC-SIGNR tetramer (C), and DC-SIGNR monomer (D), following purification by mannose-agarose affinity chromatography.

\section{DC-SIGN and DC-SIGNR Neck Region Is Required for Efficient Binding to C1q and Individual Globular Head Modules}

Tetrameric (Figure 2B) and monomeric (Figure 2C) DC-SIGN and DC-SIGNR (Figures 3B,C) coated on microtiter wells were probed with ghA, ghB, and ghC to examine whether these globular head modules were able to bind to the ECD and CRD with similar avidity. ghA, ghB, and ghC bound with much greater affinity to DC-SIGN and DC-SIGNR tetramer in comparison to the monomers, indicating that the neck is required for the individual globular heads to bind efficiently. Like C1q, the ghA, ghB, and ghC modules bound DC-SIGNR better than DC-SIGN (Figure 3B).

\section{DC-SIGN and DC-SIGNR Bind Preferentially to ghB Module}

Since C1q bound to DC-SIGN and DC-SIGNR via its globular head region, as evident from the use of ghA, ghB and ghC modules, we sought to map their specificity for DC-SIGN and DC-SIGNR binding (Figures 2B and 3B). When DC-SIGN and DC-SIGNR were coated on microtiter wells and probed with ghA, ghB, and
ghC, all three globular heads bounds DC-SIGN and DC-SIGNR in a dose-dependent manner, indicating that all three heads are capable of binding to the ligands independently. Furthermore, ghB module was preferential in binding to DC-SIGN (Figure 2B); it bound much better to DC-SIGN compared to ghA and ghC. In addition, ghB was a better binder of DC-SIGNR, as was ghA for DC-SIGNR (Figure 3B) than DC-SIGN (Figure 2B), compared with the ghC module. Although binding of ghA, ghB, and ghC to the $\mathrm{CRD}$ domain was significantly lower, the ghB module was still a better binder of DC-SIGN (Figure 2C) and DC-SIGNR (Figure 3C) monomers.

\section{The ghA Substitution Mutants Bind Differentially to DC-SIGN and DC-SIGNR}

The ability of substitution mutants $\mathrm{Arg}^{\mathrm{A} 162} \mathrm{Glu}$ and $\mathrm{Arg}^{\mathrm{A} 162} \mathrm{Ala}$ to bind to DC-SIGN and DC-SIGNR was assessed by ELISA. Both substitution mutants bound DC-SIGN (Figure 4A) and DC-SIGNR (Figure 5A) in a dose-dependent manner. DC-SIGNR was able to interact with $\mathrm{Arg}^{\mathrm{A} 162} \mathrm{Glu}$ nearly as efficiently as it did with the wild-type ghA, showing a reduction in binding of only $15 \%$ at the highest concentration of $5 \mu \mathrm{g}$ (Figure 5A). Arg ${ }^{\mathrm{A} 162} \mathrm{Ala}$, on the other hand, bound DC-SIGNR with much less affinity, showing a drop of 27\% (Figure 5A). Considering DC-SIGN and DC-SIGNR are both highly conserved, Arg ${ }^{\mathrm{A} 162} \mathrm{Glu}$ was able to interact with DC-SIGN weakly than it did with DC-SIGNR (Figures $\mathbf{4 A}$ and $\mathbf{5 A}$ ), showing a $\sim 35 \%$ reduced binding as opposed to $\sim 5 \%$ (seen with DC-SIGNR.) The mutant Arg ${ }^{\mathrm{Al}}{ }^{2} \mathrm{Ala}$ bound DC-SIGN in a similar manner as it did to its homologue DC-SIGNR showing a reduced binding of $\sim 25 \%$ (Figure 4A).

\section{ghB Substitution Mutants Bind Differentially to DC-SIGN and DC-SIGNR}

Using ELISA, we examined the ability of DC-SIGN to bind to the ghB substitution mutants $\mathrm{Arg}^{\mathrm{B} 114} \mathrm{Gln}$, ArgB114Ala, $\operatorname{Arg}^{\mathrm{B} 163} \mathrm{Glu}$, Arg ${ }^{\mathrm{B} 163} \mathrm{Ala}, \quad \mathrm{Arg}^{\mathrm{B} 129} \mathrm{Ala}, \quad \mathrm{Arg}^{\mathrm{B} 129} \mathrm{Glu}, \quad \mathrm{His}^{\mathrm{B} 117} \mathrm{Asp}, \quad \mathrm{Tyr}^{\mathrm{B} 175} \mathrm{Leu}$, and Leu ${ }^{\mathrm{B} 136} \mathrm{Gly}$ (29). All the ghB substitution mutants bound DC-SIGN (Figure 4B) and DC-SIGNR (Figure 5B) in a dosedependent manner. Substituting $\mathrm{Arg}^{\mathrm{B} 114}$ to Gln and Ala resulted in a reduction of $\sim 50 \%$ in the case of DC-SIGN (Figure $4 \mathrm{~B}$ ) and DC-SIGNR binding (Figure 5B), suggesting that the Arg residue at this position plays an important role in the C1q-DC-SIGN/ DC-SIGNR interaction (Tables 1 and 2).

Substituting the ghB mutant $\mathrm{Arg}^{\mathrm{B} 129}$ with Glu and Ala caused a slight reduction of $\sim 20 \%$ binding with DC-SIGN (Figure 4B) and up to $\sim 40 \%$ with DC-SIGNR (Figure 5B). When $\mathrm{Arg}^{\mathrm{B} 163}$ was replaced with the negatively charged Glu, its affinity for DC-SIGN and DC-SIGNR was reduced by 50 and 35\%, respectively (Figures 4B and 5B) (Tables 1 and 2); substitution with Ala resulted in $30 \%$ reduction for DC-SIGN (Figure $4 \mathbf{B}$ ) and increase by $20 \%$ for DC-SIGNR (Figure 5B) (Tables $\mathbf{1}$ and $\mathbf{2}$ ). A greater reduction in DC-SIGN and DC-SIGNR binding of $~ 60 \%$ was observed for the ghB mutant $\mathrm{His}^{\mathrm{B} 117}$ substituted for Asp. For the $\mathrm{ghB}$ module, $\mathrm{Tyr}^{\mathrm{B} 175}$ substitution to Leu had the most significant effect, showing a dramatic decrease of up to $90 \%$ in binding to DC-SIGN as well as DC-SIGNR at a concentration of $0.625 \mu \mathrm{g}$; this is not surprising due to its role in stabilizing the $\mathrm{gClq}$ domain. 
A

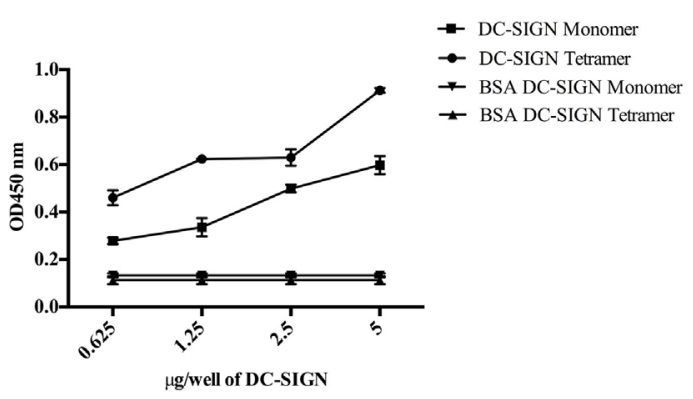

B

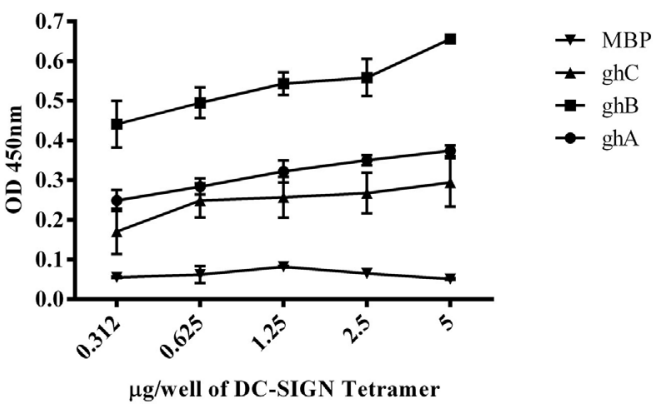

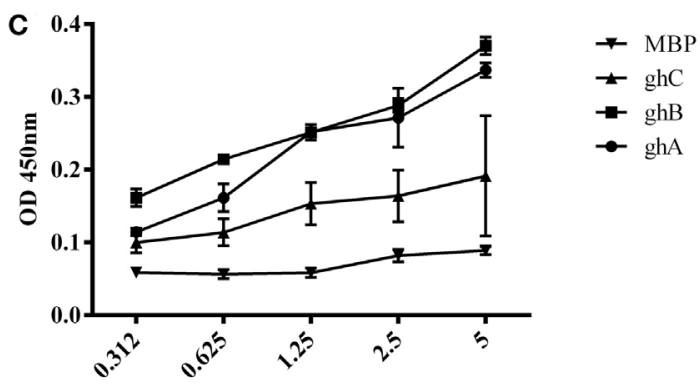

$\mu \mathrm{g} /$ well of DC-SIGN monomer

D

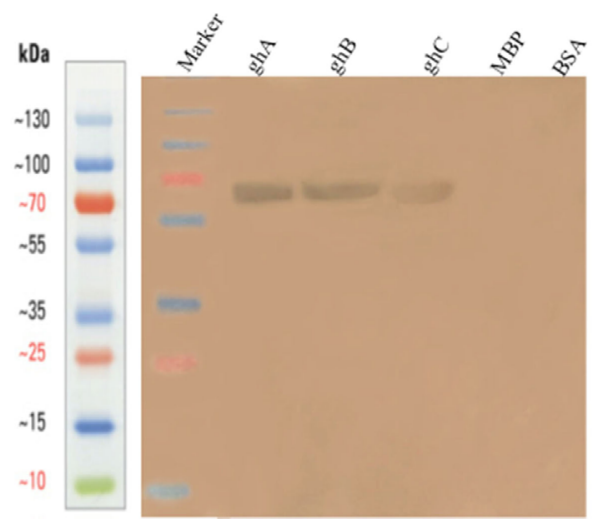

FIGURE 2 | Interaction of C1q, ghA, ghB, and ghC with DC-SIGN tetramer and monomer. (A) Microtiter wells coated with different concentrations (5, 2.5 , 1.25, $0.625 \mu \mathrm{g} /$ well) of DC-SIGN tetramer or monomer were probed with $2 \mu \mathrm{g} /$ well of C1q. Bound C1q was detected with anti-C1q polyclonal antibodies (1:1,000 in PBS) and Protein A HRP conjugate (1:1,000 in PBS). BSA was used as a negative control protein. (B) Binding of ghA, ghB, and ghC to DC-SIGN tetramer and (C) DC-SIGN monomer involved coating a range of concentrations of the respective proteins on microtiter wells, which were then incubated with a fixed concentration of ghA, ghB, ghC, and MBP $\left(2.5 \mu \mathrm{g} /\right.$ well in $5 \mathrm{mM} \mathrm{CaCl}$ buffer) at $37^{\circ} \mathrm{C}$. Binding was detected using anti-MBP monoclonal antibodies (1:5,000 in PBS) and then rabbit anti-mouse IgG-HRP (1:5,000 in PBS). (D) Far western blot to show DC-SIGN tetramer binding to membrane-bound ghA, ghB, and ghC: 15 Mg of ghA, ghB, and ghC (BSA and MBP as negative control proteins) were run on a 12\% SDS-PAGE gel and then transferred on to nitrocellulose membrane. The blot was incubated with $50 \mu \mathrm{g}$ of DC-SIGN in PBS overnight at room temperature. The bound DC-SIGN protein was detected using anti-DC-SIGN polyclonal antibodies and Protein A HRP conjugate. Bands were developed using diaminobenzidine tablets dissolved in water.

\section{Residue Leu ${ }^{136}$ on ghB, Important for IgG Binding, Is Also Involved in DC-SIGN Binding}

Using a series of globular head single residue substitution mutants (29), we sought to examine that residues in the ghB chain offered complementary binding sites for DC-SIGN. Since Leu ${ }^{\mathrm{B} 136}$ and $\mathrm{Tyr}^{\mathrm{B} 175}$ residues are considered important in maintaining the $\mathrm{gClq}$ structure as well as for IgG binding (33), we used Leu ${ }^{\mathrm{B} 136}$ substituted for Glu and $\mathrm{Tyr}^{\mathrm{B} 175}$ substituted for Leu in direct-binding

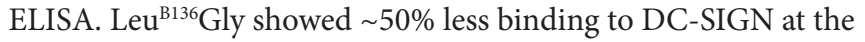
highest concentration (Figure 4B), suggesting that DC-SIGN and IgG binding sites on $\mathrm{Clq}(\mathrm{ghB})$ are overlapping.

\section{The Contributions of ghC Substitution Mutants to DC-SIGN Binding}

The substitution mutants $\mathrm{His}^{101} \mathrm{Ala}$, Arg ${ }^{156} \mathrm{Glu}$, and $\mathrm{Leu}^{170} \mathrm{Glu}$ bound to DC-SIGN in a dose-dependent manner (Figure 4C). In fact, replacing Leu ${ }^{170}$ with Glu of the ghC chain reduced binding to DC-SIGN with a decrease in $\sim 25 \%$ at the highest concentration. The ghC mutants $\mathrm{His}^{101} \mathrm{Ala}$ reduced binding by $10 \%$, suggesting that the contributions of $\mathrm{His}^{101}$ and $\mathrm{Leu}^{170}$ are comparable in the DC-SIGN-C1q interaction. The ghC substitution mutants also bound to DC-SIGNR in a dose-dependent manner.

The mutants His101Ala appeared to show 10\% better binding to DC-SIGNR with compared to wild type, whereas Leu170Glu and Arg156Glu showed reduced binding by up to $25 \%$ at the highest concentration of $5 \mu \mathrm{g}$ of DC-SIGNR (Figure 5C; Table 2).

\section{gC1qR and ghB Compete for the Same Binding Site on DC-SIGN}

In view of the recent report of $\mathrm{gClqR}, \mathrm{C} 1 \mathrm{q}$, and DC-SIGN forming a trimeric complex on immature DCs (15), we examined whether DC-SIGN has complementary and overlapping binding site for $\mathrm{Clq}$ and $\mathrm{gClqR}$. We have recently mapped the $\mathrm{gClqR}$ binding site on ghA, ghB, and ghC (30). Since ghB was found to be the preferential binder of DC-SIGN, ghB modules were tested in a competitive assay. When different concentrations of ghB and a constant concentration of $\mathrm{gClqR}$ were challenged against DC-SIGN, probing with anti-gC1qR polyclonal antibody revealed that with decreasing concentration of ghB, more $\mathrm{gCl} \mathrm{qR}$ was able to bind to solid-phase DC-SIGN (Figure 6A), thereby 


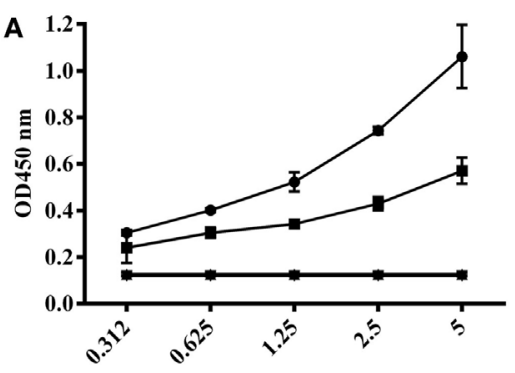

$\mu \mathrm{g} /$ well of DC-SIGNR

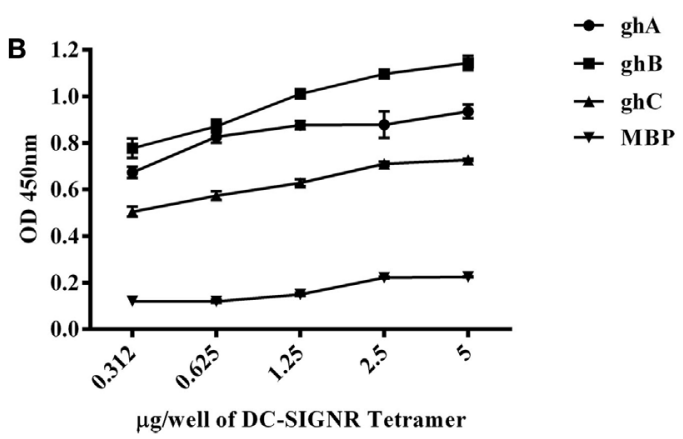

* BSA DC-SIGNR Monomer

- BSA DC-SIGNR Tetramer

- DC-SIGNR Monomer

$\rightarrow$ DC-SIGNR Tetramer

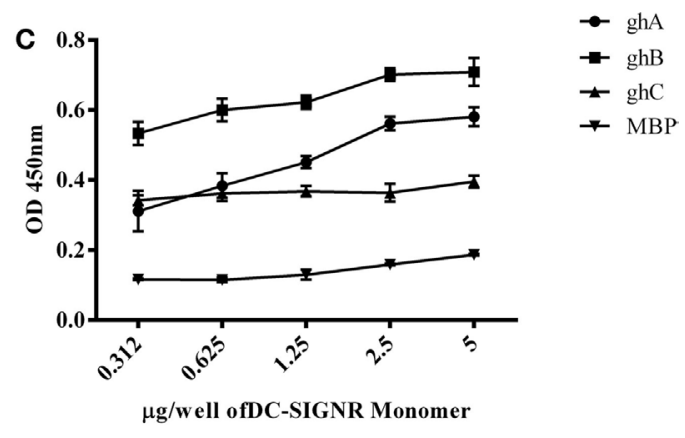

FIGURE 3 | Interaction of C1q, ghA, ghB, and ghC with DC-SIGNR tetramer and monomer. (A) ELISA to examine binding of C1q to DC-SIGNR tetramer and SIGN-R monomer: DC-SIGNR tetramer or monomer were coated at different concentrations, followed by addition of $2 \mu \mathrm{g} /$ well of C1q. Bound C1q was probed with anti-C1q polyclonal antibodies (1:1,000 in PBS) and Protein A HRP (1:1,000 in PBS), and the color was developed using o-phenylenediamine dihydrochloride. (B) Binding of ghA, ghB, and ghC to DC-SIGNR tetramer and (C) SIGN-R monomer: different concentrations of DC-SIGNR tetramer (B) and DC-SIGNR monomer (C) were coated on microtiter wells in carbonate buffer and incubated overnight at $4^{\circ} \mathrm{C}$ and then incubated with ghA, ghB, ghC, and $\mathrm{MBP}(2.5 \mu \mathrm{g} /$ well in $5 \mathrm{mM}$ $\mathrm{CaCl}_{2}$ buffer). Binding was detected using anti-MBP monoclonal antibody and rabbit anti-mouse IgG-HRP conjugate.

implying an overlapping binding site between the proteins. $5 \mu \mathrm{g}$ of DC-SIGN and $5 \mu \mathrm{g}$ of gC1qR were able to bind efficiently, showing an OD of 1 (data not shown); this binding appeared to be drastically reduced when $5 \mu \mathrm{g}$ of $\mathrm{gC} 1 \mathrm{qR}$ was allowed to compete with $5 \mu \mathrm{g}$ of ghB.

\section{C1q, ghA, ghB, and ghC Inhibit the Binding of DC-SIGN to gp120}

C1q, ghA, ghB, and ghC were able to inhibit the binding of DC-SIGN to immobilized gp120 in a dose-dependent manner. The highest concentration of $\mathrm{Clq}$, ghA, ghB, and ghC were able to significantly compete out the binding of DC-SIGN (Figure 6B).

\section{The ghA, ghB, and ghC Modules Bind to Cell Surface-Expressed DC-SIGN}

The binding of globular head modules to DC-SIGN was also performed using HEK 293 cells expressing DC-SIGN on the cell surface. The surface expression of DC-SIGN on DC-HEK cells was first confirmed with antibodies against DC-SIGN. To confirm the binding of individual globular head modules to DC-SIGN on DC-HEK cells, ghA, ghB, and ghC fused with MBP were added to the DC-HEK cells (Figure 7). Incubation of the globular head modules and probing with anti-MBP monoclonal antibodies showed that each globular head module bound on the surface of DC-HEK cells co-localizing with DC-SIGN expressed on DC-HEK cells unlike MBP (Figure 7).

\section{C1q Inhibits DC-SIGN-Mediated Transfer of HIV-1 to PBMC in Culture}

Since $\mathrm{CD} 4^{+} \mathrm{T}$ cells and macrophages are the main cells targeted by $\mathrm{HIV}-1$, we looked at the potential of $\mathrm{Clq}$, ghA, ghB, ghC, and gC1qR to modulate DC-SING-mediated transfer of HIV-1 to activated PMBCs. As shown in Figure 8A, C1q considerably inhibited viral transfer to PBMCs in a dose-dependent manner on days 4 and 7 . The globular head modules, ghA, ghB, and ghC, surprisingly did not interfere with HIV-1 transfer, neither individually nor collectively, when compared to untreated or MBPtreated control, suggesting that the collagen region of $\mathrm{C} 1 \mathrm{q}$ and/or its multivalency of the gC1q domains are likely requirement for enforcing inhibitory properties. Addition of MBP in the control wells did not significantly affect the p24 levels in comparison with untreated controls (data not shown). Furthermore, during the assay period, cellular viability was not affected by any of the protein treatments, suggesting that differences in the infectivity were not due to cell death (data not shown).

We further examined the involvement of $\mathrm{gClqR}$ with DC-SIGN in HIV-1 infection transmission (Figure 8B). gC1qR has previously been shown to inhibit CD4-gp120 interaction in HIV-1 isolates. It has also been recognized as a receptor on $\mathrm{CD}^{+} \mathrm{T}$ cells that gp41 engages with in order to cause death of bystander $\mathrm{CD}^{+} \mathrm{T}$ cells. We wanted to determine the role of $\mathrm{gC1qR}$ in DC-SIGN-mediated infection with or without C1q. Figure $8 \mathrm{~B}$ shows that $\mathrm{gCl} \mathrm{qR}$ alone did not mediate viral transfer 

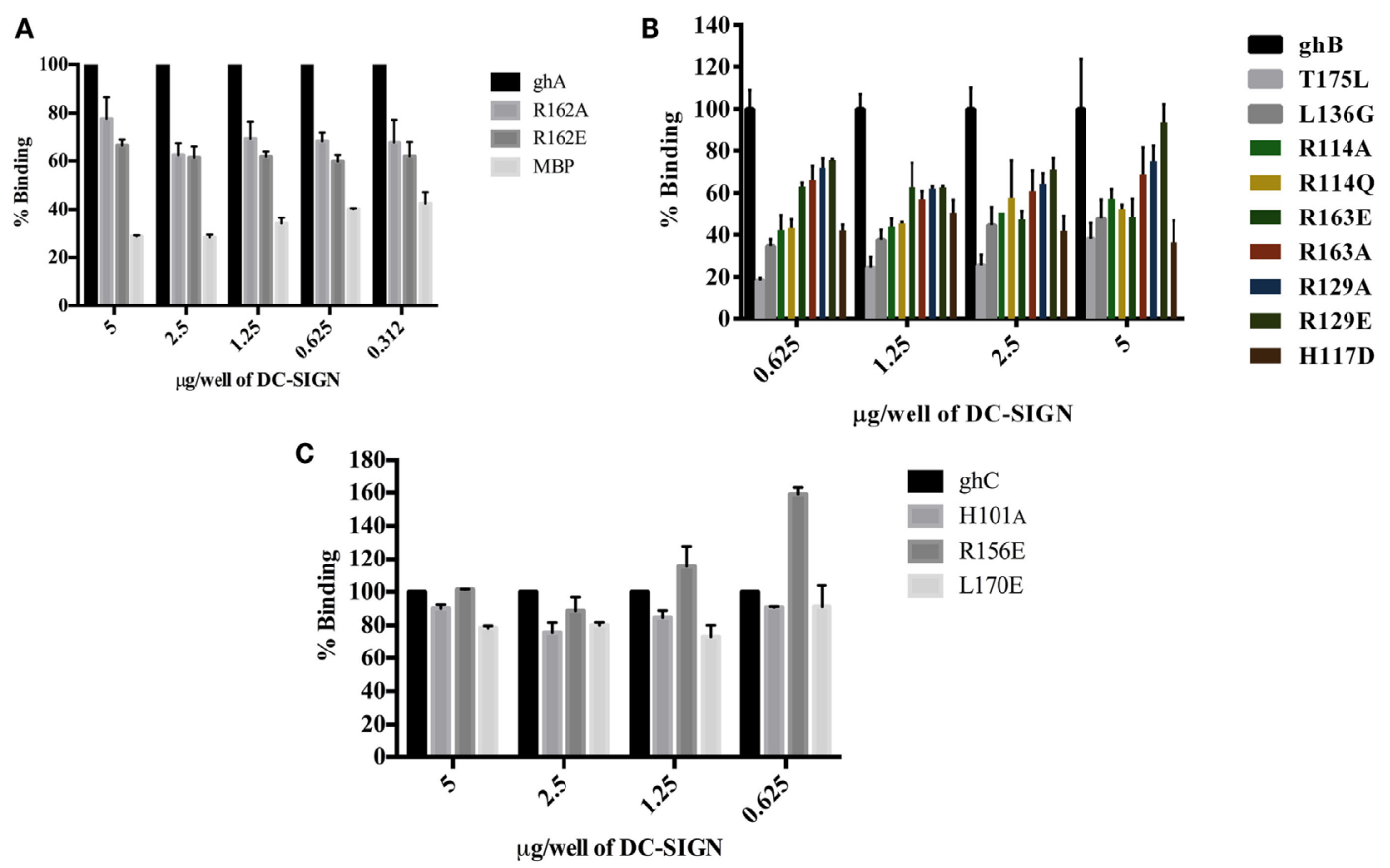

FIGURE 4 | Binding of globular head substitution mutants to DC-SIGN. Different concentrations of DC-SIGN tetramer were coated on microtiter wells in carbonate buffer overnight at $4^{\circ} \mathrm{C}$. Wells were then incubated with $2.5 \mu \mathrm{g} /$ well (in $\mathrm{CaCl}_{2}$ ) of recombinant globular head wild type and mutant proteins and probed with anti-MBP monoclonal antibody and rabbit anti-mouse IgG-HRP conjugate. Percent binding was calculated for each mutant using binding of the wild-type globular head module as 100\%. (A) Binding of ghA, ghA-R162E, and ghA-R162A to DC-SIGN; (B) binding of ghB mutants ghB-L136G, ghB-T175L, ghB-R114Q, ghB-R114A, ghB-R163A, ghB-R163E, ghB-R129E, ghB-R129A, and ghB-H117D to DC-SIGN; (C) binding of ghC mutants ghC-R156E, ghC-L170E, and ghC-H101A to DC-SIGN.

through DC-SIGN but significantly promoted viral transfer in the presence of $\mathrm{C} 1 \mathrm{q}$ as well as the three globular head modules together for up to 7 days. This suggests that the tripartite interaction between $\mathrm{C} 1 \mathrm{q}, \mathrm{gC1qR}$, and DC-SIGN enhances DC-SIGNmediated viral transfer. Thus, association of these proteins on DCs may actually promote HIV-1 infection. In addition, involvement of $\mathrm{gClqR}$ in the tripartite complex is likely to negate the protective effect of $\mathrm{Clq}$.

\section{DISCUSSION}

The role of complement in HIV-1 pathogenesis is well-documented. Complement-opsonized HIV-1 causes enhanced viral infection of $\mathrm{CD}^{+} \mathrm{T}$ cell lines (34), PBMCs, monocytes, and macrophages (35). DC-SIGN on the surface of immature DCs is involved in the capture of $\mathrm{C} 3$ opsonized $\mathrm{R} 5$ and $\mathrm{X} 4$ tropic HIV-1 and enhanced transmission to T cells (36). C1q can bind to gp41 directly in an antibody-independent manner and activate the classical pathway (16); however, this leads to an enhanced infection of complement receptor-bearing cells (37). To escape complement-mediated destruction, HIV-1 uses follicular DCs as a viral reservoir (38), following its internalization via CR2, and remains within its protective recycling endosome. Following emergence from the endosome to the cell surface, HIV-1 infects follicular $\mathrm{T}$ cells through CD4. HIV-1 opsonized with C3b interacts with CR1 on erythrocytes with factor I dissociating erythrocytes from this complex and converting $\mathrm{C} 3 \mathrm{~b}$ to $\mathrm{iC} 3 \mathrm{~b}$ and C3d. C3d opsonized HIV-1 is then able to bind to CR2 on B cells (39). In this study, we have examined complement-independent interaction of C1q with HIV-1 via DC-SIGN.

$\mathrm{C} 1 \mathrm{q}$ is a charge pattern recognition protein that binds to a variety of ligands via its gC1q domain (19). Following its ability to interact with DC-SIGNR (32), Hosszu et al. recently have shown that $\mathrm{C} 1 \mathrm{q}$ also recognizes a peptide derived from its homolog DC-SIGN (15). In the current study, we made use of the availability of recombinant individual globular head modules of $\mathrm{C} 1 \mathrm{q}$ (ghA, ghB, and ghC) and its substitution mutants to establish that C1q binds DC-SIGN (and DC-SIGNR) via its gC1q domain.

Structure-function studies have demonstrated that the CRD region of DC-SIGN is the specific site for ligand binding and only funcions in the presence of the neck region within the ECD (12). We performed a series of binding experiments involving both the tetrameric forms of DC-SIGN and DC-SIGNR (comprising of the ECD and CRD region) as well as the monomeric forms, which only consist of the CRD region. We asked the question whether DC-SIGN and DC-SIGNR binding sites for C1q (and its gC1q domain) lies within their CRD region, or the $\alpha$-helical neck region also plays an important role in these interactions. Both proteins have an increased affinity for glycoproteins containing high mannose oligosaccharides, such as mannan (40), gp120 (10), and ICAM-3 (41), via the CRD region. Here, individual globular head modules bound better to the tetrameric forms of DC-SIGN 


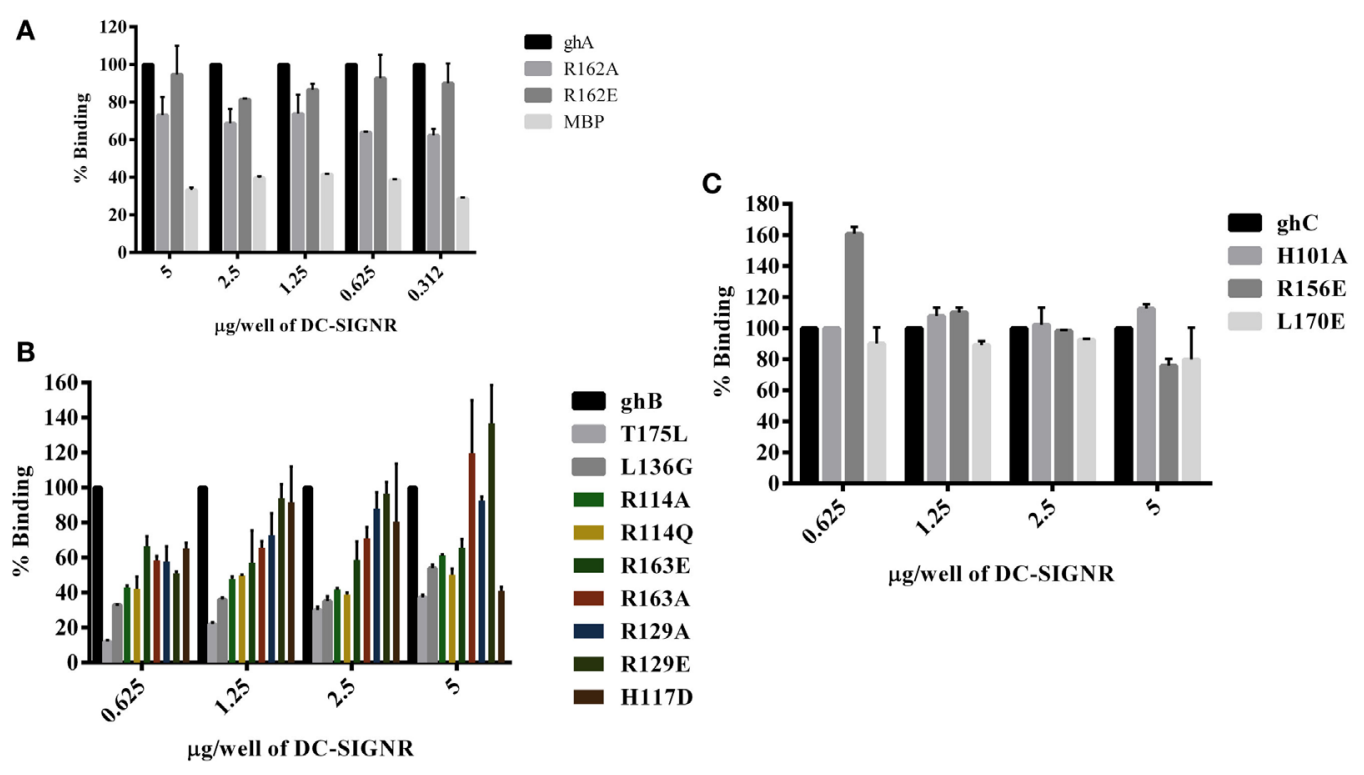

FIGURE 5 | Binding of globular head substitution mutants to DC-SIGNR. Different concentrations of DC-SIGNR tetramer were coated on microtiter wells in carbonate buffer overnight at $4^{\circ} \mathrm{C}$ and then incubated with $2.5 \mu \mathrm{g} /$ well of recombinant globular head wild type and mutant proteins and probed with anti-MBP monoclonal antibody and rabbit anti-mouse IgG-HRP conjugate. Percent binding was calculated for each mutant using binding of the wild-type globular head module as 100\%. (A) Binding of ghA, ghA-R162E and ghA-R162A to DC-SIGNR; (B) binding of ghB mutants ghB-L136G, ghB-T175L, ghB-R114Q, ghB-R114A, ghB-R163A, ghB-R163E, ghB-R129E, ghB-R129A, and ghB-H117D to DC-SIGNR; (C) binding of ghC mutants ghC-R156E, ghC-L170E, and ghC-H101A to DC-SIGNR.

TABLE 1 | Bindings of globular head modules and its mutants with DC-SIGN (\% binding \pm SD).

\begin{tabular}{cc}
\hline ghA & $100.00 \pm 0.0$ \\
R162A & $77.71 \pm 8.85$ \\
R162E & $66.41 \pm 2.38$ \\
ghB & $100.0 \pm 23.62$ \\
R129E & $93.91 \pm 8.34$ \\
R129A & $75.05 \pm 7.22$ \\
R163A & $68.76 \pm 12.78$ \\
R114A & $57.37 \pm 4.45$ \\
R114Q & $52.46 \pm 1.94$ \\
R163E & $48.33 \pm 8.89$ \\
L136G & $47.74 \pm 9.17$ \\
T175L & $37.92 \pm 7.50$ \\
H117D & $36.35 \pm 10.28$ \\
ghC & $100.00 \pm 0.00$ \\
R156E & $101.41 \pm 0.27$ \\
H101A & $90.20 \pm 2.27$ \\
L170E & $78.32 \pm 1.47$ \\
\hline
\end{tabular}

and DC-SIGNR as opposed to just the CRD region alone, indicating that the neck region, and hence, multimerization is needed to facilitate $\mathrm{C} 1 \mathrm{q}$ binding. The neck region of DC-SIGN and DC-SIGNR interestingly differ most in their $\alpha$ helical structures (8) as the 23 amino acid repeats only show the first half of each repeat presenting a pattern of hydrophobic residues spaced at intervals, a feature that is abundant in most dimeric and trimeric coiled-coils (42).

We also found that the ghB module bound better to DC-SIGN and DC-SIGNR. Previous studies have identified ghB as a key
TABLE 2 | Bindings of globular head modules and its mutants with DC-SIGNR (\% binding \pm SD).

\begin{tabular}{cc}
\hline ghA & $100.00 \pm 0.00$ \\
R162E & $94.78 \pm 15.08$ \\
R162A & $73.17 \pm 9.54$ \\
ghB & $100.00 \pm 0.00$ \\
R129E & $136.70 \pm 21.82$ \\
R163A & $119.68 \pm 30.09$ \\
R129A & $92.55 \pm 2.26$ \\
R163E & $65.69 \pm 4.89$ \\
R114A & $61.44 \pm 0.38$ \\
L136G & $53.99 \pm 1.88$ \\
R114Q & $50.27 \pm 3.39$ \\
H117D & $40.96 \pm 2.26$ \\
T175L & $37.23 \pm 1.50$ \\
ghC & $100.00 \pm 0.00$ \\
H101A & $112.60 \pm 2.86$ \\
L170E & $79.81 \pm 20.40$ \\
R156E & $75.77 \pm 4.62$ \\
\hline
\end{tabular}

module of the gC1q domain in binding to IgG, PTX3, and CRP $(43,44)$. Interestingly, C1q and ghB bound DC-SIGNR better than DC-SIGN, despite $77 \%$ sequence similarity. We also expressed and purified globular head mutants (29) where single amino acid residues were substituted in order to localize key residues involved in $\mathrm{C} 1 \mathrm{q}$ interaction with its various ligands. These mutants were designed based on the crystal structure and are the residues known to be important in binding to various C1q ligands (43). It appears that IgG and DC-SIGN binding sites on ghB are overlapping and shared, including Lys ${ }^{136}$ and 


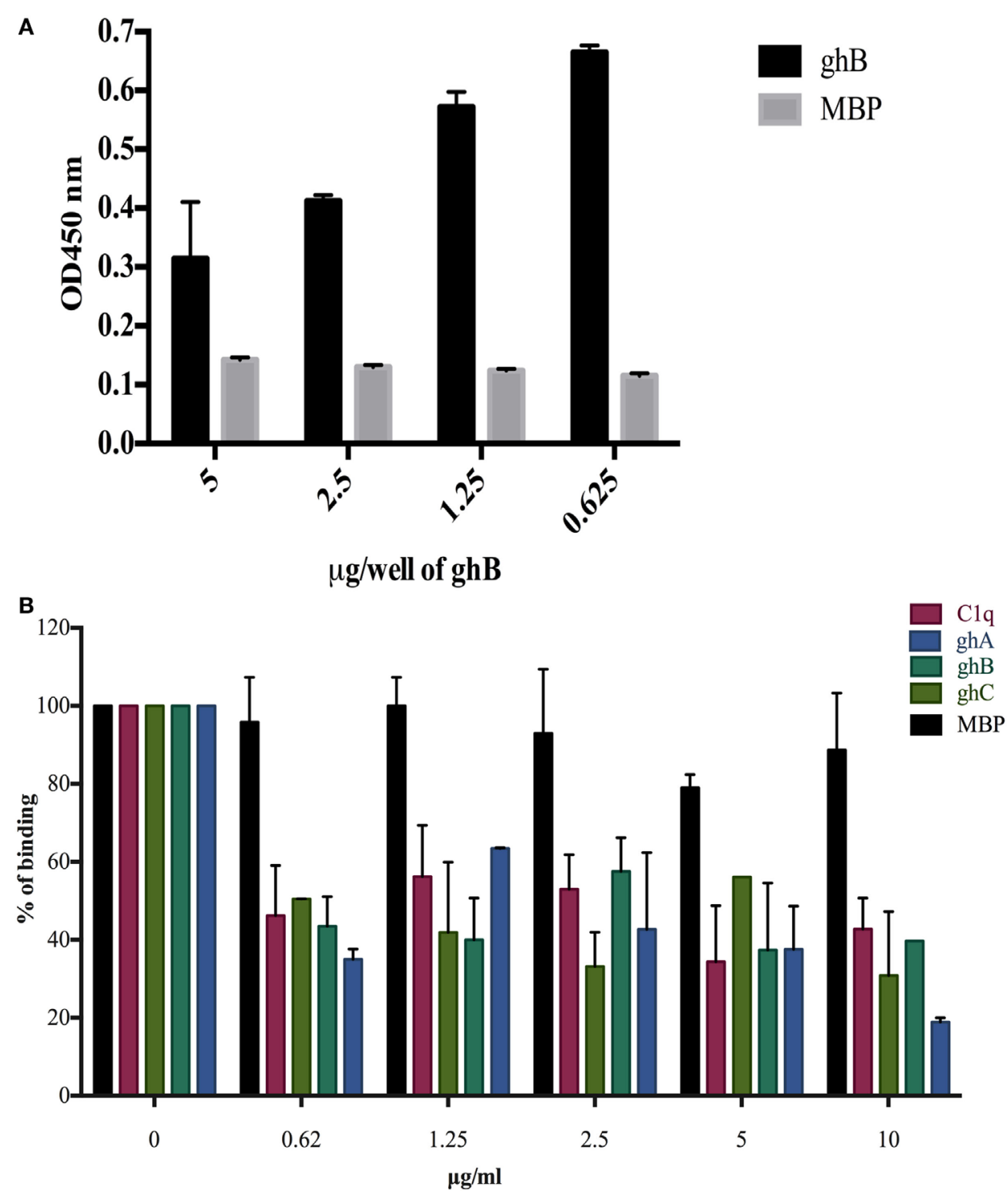

FIGURE 6 | Competitive inhibition of DC-SIGN: HIV-1 gp120 interaction by globular head modules and gC1qR. (A) ELISA to assess whether gC1qR and ghB directly compete for the same binding site on DC-SIGN: DC-SIGN was coated at $5 \mu \mathrm{g} /$ well overnight at $4^{\circ} \mathrm{C}$. Wells were blocked with $2 \%$ BSA in PBS for $2 \mathrm{~h}$ at $37^{\circ} \mathrm{C}$. gC1qR $\left(5 \mu \mathrm{g} /\right.$ well) and different concentrations of $\mathrm{ghB}\left(5,2.5,1.25,0.625 \mu \mathrm{g} /\right.$ well) were added in buffer containing $5 \mathrm{mM} \mathrm{CaCl}_{2}$. Incubation was carried out at $37^{\circ} \mathrm{C}$ for $1.5 \mathrm{~h}$ and $4^{\circ} \mathrm{C}$ for $1.5 \mathrm{~h}$. Following repeated washes, bound gC1qR was probed using rabbit anti-gC1qR polyclonal antibodies $(1: 1,000)$ and Protein A-HRP $(1: 1,000)$. Color was developed using o-phenylenediamine dihydrochloride substrate; (B) competition between DC-SIGN tetramer and C1q globular head modules to bind solid-phase gp120. Microtiter wells were coated with $250 \mathrm{ng}$ of gp120. Various concentrations of ghA, ghB, ghC, and C1q and constant $2.5 \mu \mathrm{g} / \mathrm{mL}$ of DC-SIGN were incubated at $37^{\circ} \mathrm{C}$ for $1 \mathrm{~h}$ and then at $4^{\circ} \mathrm{C}$ for $1 \mathrm{~h}$. The binding of DC-SIGN to gp120 in the presence of globular heads or C1q was detected using rabbit anti-DC antibody (1:500), probed with Protein A HRP (1:5,000). DC-SIGN alone binding to gp120 was used as 100\%.

$\mathrm{Tyr}^{175}$ on ghB, which have been previously shown to be important for binding to IgG (29) and for gC1q assembly (45). We also examined the roles of $\mathrm{Arg}^{114}, \mathrm{Arg}^{129}$, and $\mathrm{Arg}^{163}$ of the ghB module since arginine residues have previously been shown to be important for the C1q-IgG interaction (46). Moreover, Hosszu et al. have reported that $\mathrm{Clq}$ binds DC-SIGN via its IgG binding site (15). Our results highlighted the significance of $\mathrm{Arg}^{114}$ in $\mathrm{Clq}$ interaction with DC-SIGN and DC-SIGNR (Figures 4B and 5B). Substituting $\mathrm{Arg}^{114}$ with the polar residue
Glutamine and hydrophobic residue Ala led to $\sim 80 \%$ reduction, highlighting a very important role for Arginine ${ }^{114}$ of B chain in C1q-DC-SIGN interaction. In addition, Tyr $^{175}$ appears critical for $\mathrm{C} 1 \mathrm{q}$ interaction with DC-SIGN and DC-SIGNR (Figures 4B and $5 \mathrm{~B}$ ); the binding analysis revealed a dramatic reduction (82\% for DC-SIGN and 90\% for DC-SIGNR following substitution of Tyr with Leu). This is not the first time $\mathrm{Tyr}^{175}$ has been shown to be a critical residue in gC1q binding (33). Gadjeva et al. have shown that this residue mainly constitutes $\mathrm{C} 1 \mathrm{q}$ binding to 


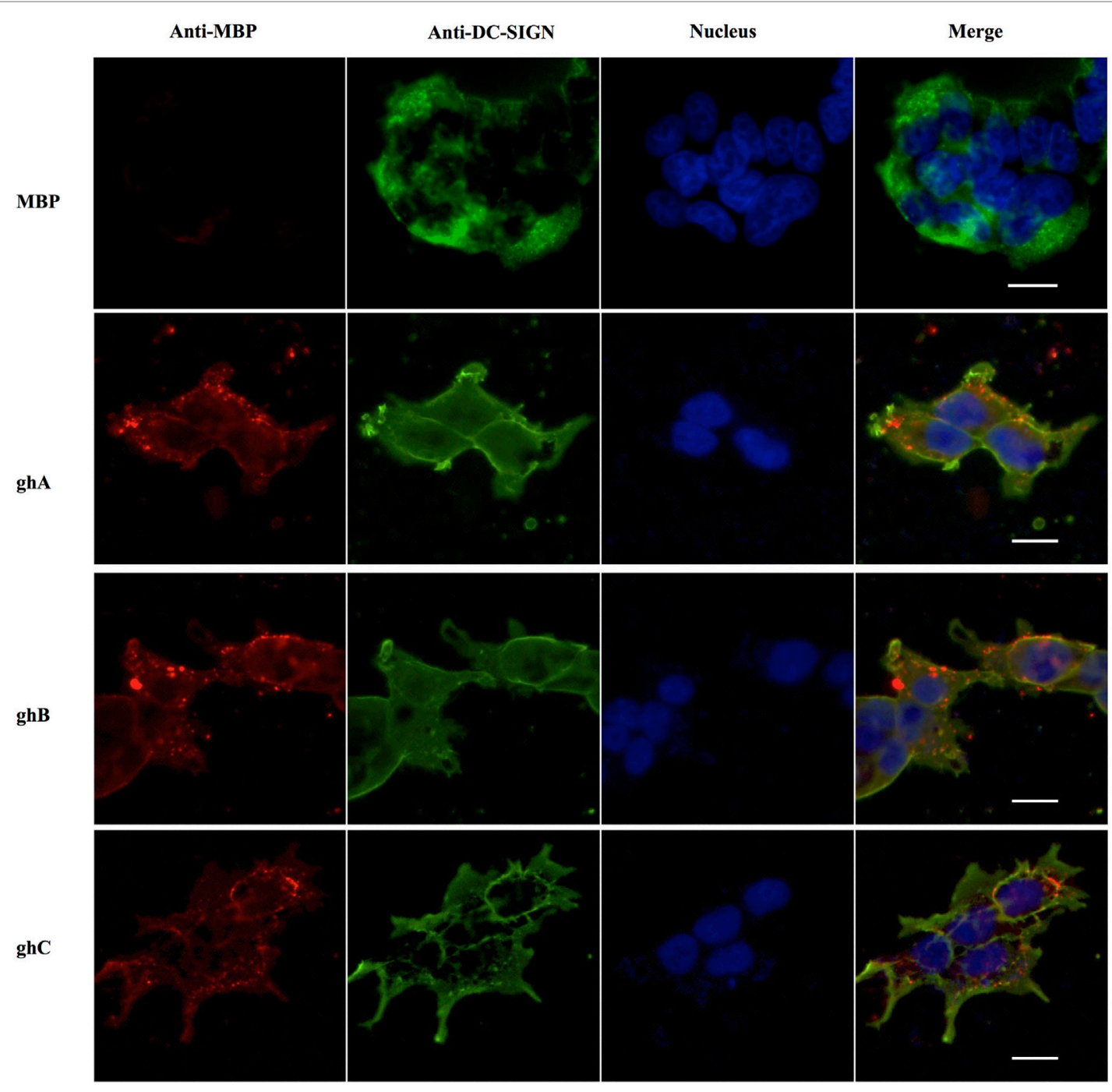

FIGURE 7 | In vitro binding of globular heads modules to DC-SIGN expressed on HEK cells. DC-SIGN-expressing HEK cells (DC-HEK cells) were incubated with recombinant globular head modules (ghA, ghB, ghC) and MBP as control for $30 \mathrm{~min}$ at $37^{\circ} \mathrm{C}$. DC-HEK cells were fixed with $4 \%$ paraformaldehyde, washed and blocked with 5\% FCS, and probed with mouse anti MBP antibody to detect the presence of MBP fused globular head modules and rabbit anti DC-SIGN to detect DC-SIGN expressed on the cells. Goat anti-mouse secondary antibody conjugated with Alexa Fluor 568 was used to detect binding of globular heads whereas DC-SIGN expression was visualized using goat anti-rabbit lgG conjugated with Alexa Fluor 488 antibody. Scale bar $20 \mu m$.

IgM. Overall, our binding studies suggest that $\operatorname{Tyr}^{175}$ and $\operatorname{Arg}^{114}$ of ghB are critical for the C1q-DC-SIGN and C1q-DC-SIGNR interaction.

The known dual roles of DC-SIGN as a facilitator of adaptive immune response as well as promoter of HIV-1 infection prompted us to examine if innate immune soluble factors such as $\mathrm{C} 1 \mathrm{q}$ and $\mathrm{gCl} \mathrm{qR}$ can potentially modulate viral transmission via DC-SIGN (47), similar to reports involving $\mathrm{CD}^{+} \mathrm{T}$ cells (48) and a lectin drug GRFT (Griffithsia) isolated from the red algae (49). We also included DC-SIGNR (DC-SIGN-related), a homolog of DC-SIGN, in our study. DC-SIGN-R is expressed on endothelium including liver sinusoidal (50), lymph node sinuses, and placental capillary (8). DC-SIGNR can bind ICAM-3 as well as gp120 to facilitate HIV-1 viral infection (50). As a receptor for bacterial dextrans (51) and capsular pneumococcal polysaccharide of Streptococcus pneumoniae, DC-SIGN-R can cause proteolysis of C3 (32). DC-SIGN-R is shown to be highly expressed by spleen marginal zone macrophages (MZM) and lymph node macrophages (52). SIGN-R1 (mouse homologue) in MZM interacts with $\mathrm{C} 1 \mathrm{q}$ in the spleen and enhances apoptotic cell clearance via activation of the classical pathway (53).

The transmembrane envelope gp41 protein of $\mathrm{HIV}-1$ is known to interact with C1q (54) through its A chain (19), leading to complement activation but no viral lysis (55). Instead, the virus is transmitted to complement receptor bearing cells such as macrophages and $\mathrm{CD} 4^{+} \mathrm{T}$ cells allowing infection to take place $(37,54,56,57)$. HIV-1-infected $\mathrm{CD}^{+} \mathrm{T}$ cells can activate the classical pathway via shedding of gp120, leading to unmasking of the gp41 epitope 601-613 available for interaction 

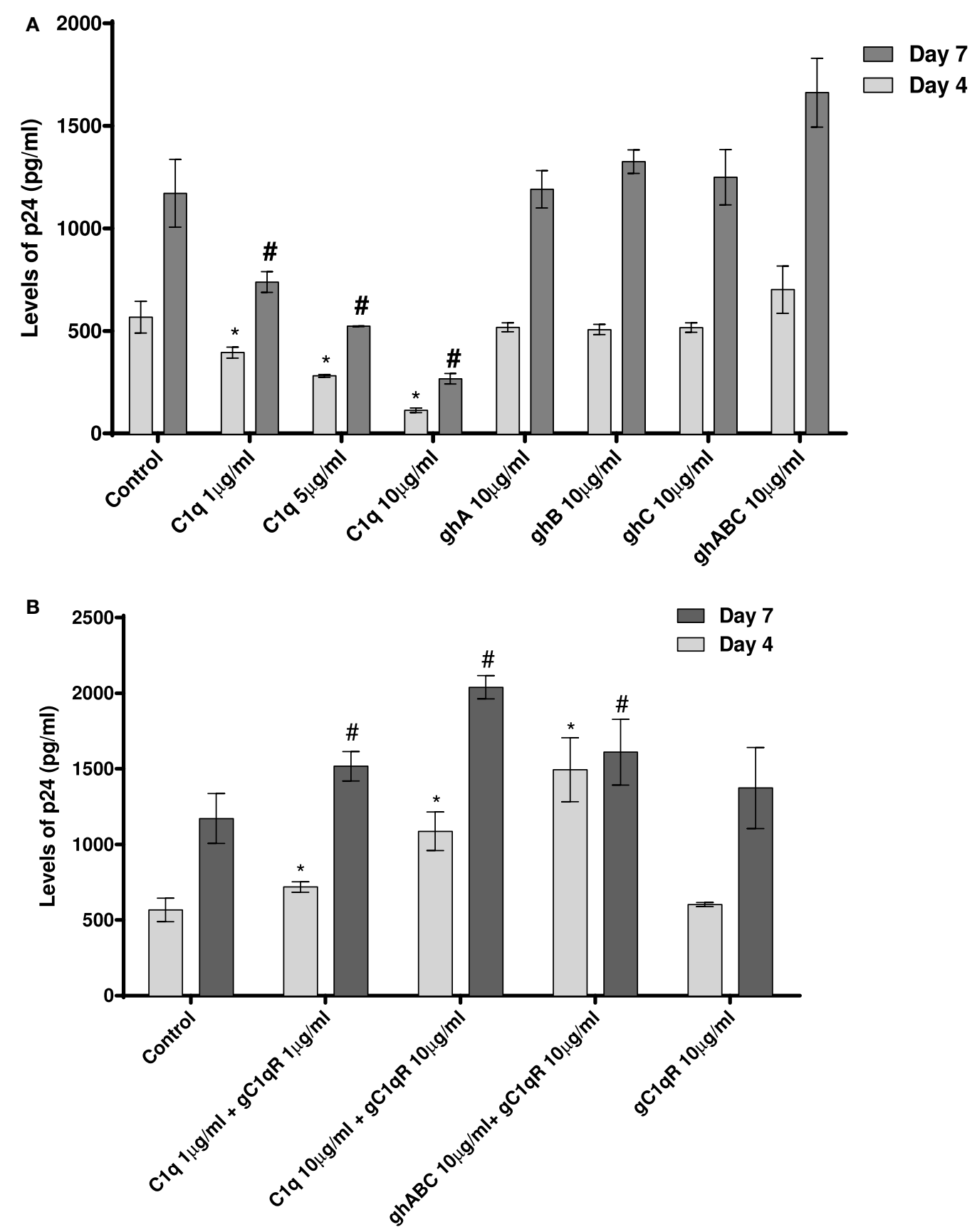

FIGURE 8 | HIV transfer assay mediated by DC-SIGN. Cell surface DC-SIGN expressing HEK (DC-HEK) cells were grown in a 12-well plate to form a confluent layer. Different concentrations of proteins were added to the cells and incubated for $2 \mathrm{~h}$ for binding. Unbound proteins were removed and cells were challenged with $2.5 \mathrm{ng} / \mathrm{mL}$ p24 of HIV-1 (SF-162 strain) for $1 \mathrm{~h}$. Unbound virus was washed off and cells were co-cultured with PHA-activated PBMCs for $24 \mathrm{~h}$. PBMCs were separated from the DC-HEK monolayer and cultured separately for 7 days to determine viral titer of the supernatants collected on days 4 and 7 . (A) C1q, ghA, ghB, ghC, and ghABC; (B) gC1qR in presence of C1q, ghA, ghB, ghC, and ghABC. Data represent mean \pm SD. $P<0.05$ is considered significant. * and \# indicate statistical significance in comparison to untreated controls of days 4 and 7 , respectively.

with $\mathrm{C} 1 \mathrm{q}$ (23). C1q is also involved in a range of processes independent to its complement functions $(58,59)$, including DC differentiation (60). C1q, along with its globular head receptor $\mathrm{gC1qR}$ and DC-SIGN, can co-localize on the surface of blood precursor DCs to promote DC differentiation (15). gC1qR, a multifunctional pathogen recognition receptor $(61,62)$, can also interact with gp41 of HIV-1 (17) on uninfected $\mathrm{CD} 4^{+} \mathrm{T}$ cells and upregulate NK cell ligand NKP44-L, rendering healthy CD4 ${ }^{+} \mathrm{T}$ cells susceptible to NK cell lysis. Since DC-SIGN is a receptor for HIV-1 through its binding to gp120, it is interesting that it 


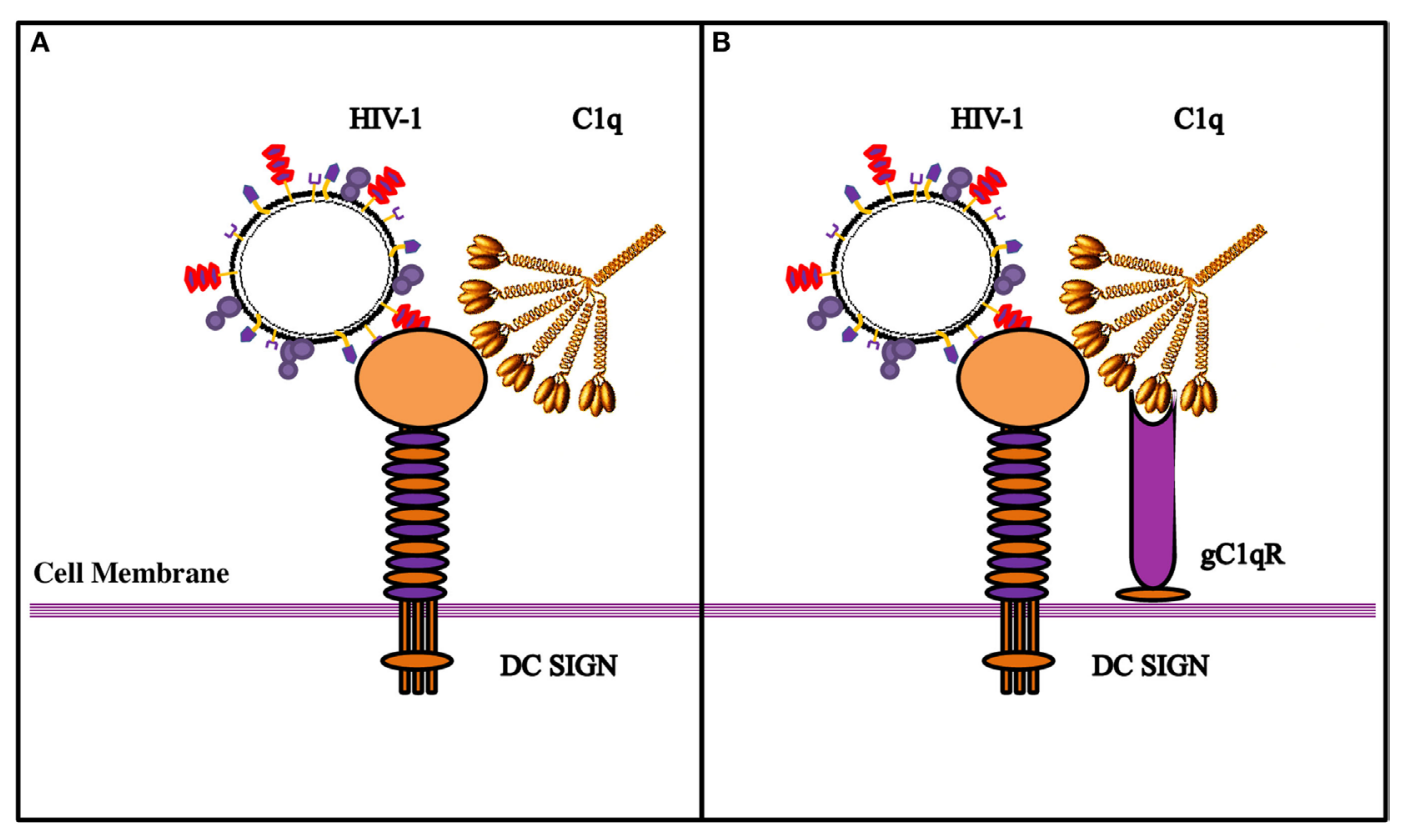

FIGURE 9 | Diagrammatic model explaining the possible implications of the tripartite molecular interplay between DC-SIGN, C1q, and gC1qR. (A) By virtue of its ability to bind to DC-SIGN on the cell surface, C1q is likely to inhibit interaction between DC-SIGN and HIV-1 gp120, resulting in the inhibition of viral transfer. (B) On the DC/Monocyte surface, a trimolecular receptor complex is formed between gC1qR, C1q, and DC-SIGN. Although each of these molecules can bind the HIV-1 virus independently, we postulate that it is the binding of the HIV-1 gp-41 to both gC1qR and C1q that initiates the membrane fusion before the final binding of gp120 to DC-SIGN and/or CD4, eventually allowing the internalization of the virus. It is possible that HIV-1 interaction with DC/ monocytes causes recruitment of $\mathrm{gC1qR}$ to the cell surface, or its secretion, which in turn, can bind to C1q globular heads, thereby neutralizing the protection offered by C1q.

co-localizes with $\mathrm{C} 1 \mathrm{q}$ and $\mathrm{gClqR}$, the two proteins, also known for HIV-1 binding and transmission of the viral infection. Such association forming a trimolecular unit on the target cell surface may create a vehicle that promotes pathogen entry and immunosuppression (15).

Wewanted to examine ifC1q-DC-SIGNinteraction modulated HIV-1 transfer. We found that full length C1q but not its individual globular heads, suppressed DC-SIGN-mediated HIV-1 transfer to activated PBMCs. Curiously, addition of $\mathrm{gC1qR}$ negated the protective effects of $\mathrm{Clq}$ by enhancing DC-SIGN-mediated viral transfer. gC1qR, as an inhibitor of HIV-1 infection, can block the interaction between CD4 and gp120 and prevent viral entry (24). Since DC-SIGN binds to gp120 and gC1qR to gp41, both promoting infection, we can consider that even if $\mathrm{gClqR}$ does interfere with the DC-SIGN-gp120 interaction, its active binding site for gp41 is still available to facilitate infection. The increased viral transmission of $\mathrm{gClqR}$ seen when in association with $\mathrm{Clq}$ suggests that $\mathrm{C} 1 \mathrm{q}$ bound to $\mathrm{gC1qR}$ can enhance its function. It is possible that C1q plays a protective role by blocking access of gp120 to DC-SIGN (Figure 9). This can happen if C1q shares binding sites on DC-SIGN. The globular heads, individually or in combination, did not appear to inhibit virus transmission unlike full length $\mathrm{C} 1 \mathrm{q}$, suggesting that the collagen domain of $\mathrm{C} 1 \mathrm{q}$ and/ or probably oligomeric form of $\mathrm{Clq}$ is required for the observed inhibitory effect.

In summary, we found that gC1qR can alter C1q-DC-SIGN interaction in a way that it promotes viral transfer, thus neutralizing the protective effect of C1q. The tripartite complex involving DC-SIGN-gC1qR-C1q probably leads to an increase in the distance between DC-SIGN and C1q that permits DC-SIGN interaction with gp120; this allows DC-SIGN and gC1qR to bind to the virus with enhanced affinity (Figure 9).

\section{AUTHOR CONTRIBUTIONS}

LP, HP, BP, and AK carried out crucial experiments; MA-M, LK, BG, and DM provided important reagents; TM supervised few experiments and helped with manuscript preparation; UK led the research, conceived the experiments, and drafted the manuscript.

\section{FUNDING}

BG would like to acknowledge support from the National Institute of Allergy and Infectious Diseases R01 AI 060866 and R01 AI-084178. 


\section{REFERENCES}

1. Caparros E, Munoz P, Sierra-Filardi E, Serrano-Gomez D, Puig-Kroger A, Rodriguez-Fernandez J, et al. DC-SIGN ligation on dendritic cells results in ERK and PI3K activation and modulates cytokine production. Blood (2006) 107:3950-8. doi:10.1182/blood-2005-03-1252

2. Gringhuis SI, den Dunnen J, Litjens M, van HH, van Kooyk Y, Geijtenbeek TB. C-type lectin DC-SIGN modulates Toll-like receptor signaling via Raf-1 kinase-dependent acetylation of transcription factor NF-kappaB. Immunity (2007) 26:605-16. doi:10.1016/j.immuni.2007.03.012

3. den Dunnen J, Gringhuis SI, Geijtenbeek TB. Innate signaling by the C-type lectin DC-SIGN dictates immune responses. Cancer Immunol Immunother (2009) 58:1149-57. doi:10.1007/s00262-008-0615-1

4. Geijtenbeek TB, Torensma R, van Vliet SJ, van Duijnhoven GC, Adema GJ, van Kooyk Y, et al. Identification of DC-SIGN, a novel dendritic cell-specific ICAM-3 receptor that supports primary immune responses. Cell (2000) 100:575-85. doi:10.1016/S0092-8674(00)80693-5

5. Geijtenbeek TB, van Duijnhoven GC, van Vliet SJ, Krieger E, Vriend G, Figdor $\mathrm{CG}$, et al. Identification of different binding sites in the dendritic cell-specific receptor DC-SIGN for intercellular adhesion molecule 3 and HIV-1. J Biol Chem (2002) 277:11314-20. doi:10.1074/jbc.M111532200

6. Martinez O, Brackenridge S, El-Idrissi Mel A, Prabhakar BS. DC-SIGN, but not sDC-SIGN, can modulate IL-2 production from PMA-and anti-CD3-stimulated primary human CD4 T cells. Int Immunol (2005) 17:769-78. doi:10.1093/ intimm/dxh258

7. Maeda N, Nigou J, Herrmann JL, Jackson M, Amara A, Lagrange PH, et al. The cell surface receptor DC-SIGN discriminates between Mycobacterium species through selective recognition of the mannose caps on lipoarabinomannan. J Biol Chem (2003) 278:5513-6. doi:10.1074/jbc.C200586200

8. Mitchell DA, Fadden AJ, Drickamer K. A novel mechanism of carbohydrate recognition by the C-type lectins DC-SIGN and DC-SIGNR. Subunit organization and binding to multivalent ligands. J Biol Chem (2001) 276:28939-45. doi:10.1074/jbc.M104565200

9. Manches O, Frleta D, Bhardwaj N. Dendritic cells in progression and pathology of HIV infection. Trends Immunol (2014) 35:114-22. doi:10.1016/j. it.2013.10.003

10. Geijtenbeek TB, Kwon DS, Torensma R, van Vliet SJ, van Duijnhoven GC, Middel J, et al. DC-SIGN, a dendritic cell-specific HIV-1-binding protein that enhances trans-infection of T cells. Cell (2000) 100:587-97. doi:10.1016/ S0092-8674(00)80694-7

11. Pohlmann S, Zhang J, Baribaud F, Chen Z, Leslie GJ, Lin G, et al. Hepatitis C virus glycoproteins interact with DC-SIGN and DC-SIGNR. J Virol (2003) 77:4070-80. doi:10.1128/JVI.77.7.4070-4080.2003

12. Lozach PY, Lortat-Jacob H, de Lacroix dL, Staropoli I, Foung S, Amara A, et al. DC-SIGN and L-SIGN are high affinity binding receptors for hepatitis C virus glycoprotein E2. J Biol Chem (2003) 278:20358-66. doi:10.1074/jbc. M301284200

13. Curtis BM, Scharnowske S, Watson AJ. Sequence and expression of a membrane-associated C-type lectin that exhibits CD4-independent binding of human immunodeficiency virus envelope glycoprotein gp120. Proc Natl Acad Sci U S A (1992) 89:8356-60. doi:10.1073/pnas.89.17.8356

14. Sarkar R, Mitra D, Chakrabarti S. HIV-1 gp120 protein downregulates Nef induced IL-6 release in immature dentritic cells through interplay of DC-SIGN. PLoS One (2013) 8:e59073. doi:10.1371/journal.pone.0059073

15. Hosszu KK, Valentino A, Vinayagasundaram U, Vinayagasundaram R, Joyce MG, Ji Y, et al. DC-SIGN, C1q, and gC1qR form a trimolecular receptor complex on the surface of monocyte-derived immature dendritic cells. Blood (2012) 120:1228-36. doi:10.1182/blood-2011-07-369728

16. Ebenbichler CF, Thielens NM, Vornhagen R, Marschang P, Arlaud GJ, Dierich MP. Human immunodeficiency virus type 1 activates the classical pathway of complement by direct $\mathrm{C} 1$ binding through specific sites in the transmembrane glycoprotein gp41.J ExpMed (1991) 174:1417-24. doi:10.1084/jem.174.6.1417

17. Fausther-Bovendo H, Vieillard V, Sagan S, Bismuth G, Debre P. HIV gp41 engages gC1qR on CD4+ T cells to induce the expression of an NK ligand through the PIP3/H2O2 pathway. PLoS Pathog (2010) 6:e1000975. doi:10.1371/journal.ppat.1000975

18. Thielens NM, Bally IM, Ebenbichler CF, Dierich MP, Arlaud GJ. Further characterization of the interaction between the $\mathrm{C} 1 \mathrm{q}$ subcomponent of human
$\mathrm{C} 1$ and the transmembrane envelope glycoprotein gp41 of HIV-1. J Immunol (1993) 151:6583-92.

19. Kishore U, Gupta SK, Perdikoulis MV, Kojouharova MS, Urban BC, Reid $\mathrm{KB}$. Modular organization of the carboxyl-terminal, globular head region of human C1q A, B, and C chains. J Immunol (2003) 171:812-20.

20. Thielens NM, Tacnet-Delorme P, Arlaud GJ. Interaction of C1q and mannan-binding lectin with viruses. Immunobiology (2002) 205:563-74. doi:10.1078/0171-2985-00155

21. Pinter A, Honnen WJ, Tilley SA, Bona C, Zaghouani H, Gorny MK, et al. Oligomeric structure of gp41, the transmembrane protein of human immunodeficiency virus type 1. J Virol (1989) 63:2674-9.

22. Marschang P, Kruger U, Ochsenbauer C, Gurtler L, Hittmair A, Bosch V, et al. Complement activation by HIV-1-infected cells: the role of transmembrane glycoprotein gp41. J Acquir Immune Defic Syndr Hum Retrovirol (1997) 14:102-9. doi:10.1097/00042560-199702010-00002

23. Caffrey M. Model for the structure of the HIV gp41 ectodomain: insight into the intermolecular interactions of the gp41 loop. Biochim Biophys Acta (2001) 1536:116-22. doi:10.1016/S0925-4439(01)00042-4

24. Szabo J, Cervenak L, Toth FD, Prohaszka Z, Horvath L, Kerekes K, et al. Soluble $\mathrm{gC1q}-\mathrm{R} / \mathrm{p} 33$, a cell protein that binds to the globular "heads" of C1q, effectively inhibits the growth of HIV-1 strains in cell cultures. Clin Immunol (2001) 99:222-31. doi:10.1006/clim.2001.5013

25. Kittlesen DJ, Chianese-Bullock K, Yao ZQ, Braciale TJ, Hahn YS. Interaction between complement receptor $\mathrm{gClqR}$ and hepatitis $\mathrm{C}$ virus core protein inhibits T-lymphocyte proliferation. JClin Invest (2000) 106:1239-49. doi:10.1172/JCI10323

26. Matthews DA, Russell WC. Adenovirus core protein V interacts with p32 - a protein which is associated with both the mitochondria and the nucleus. J Gen Virol (1998) 79( Pt 7):1677-85. doi:10.1099/0022-1317-79-7-1677

27. Wang Y, Finan JE, Middeldorp JM, Hayward SD. P32/TAP, a cellular protein that interacts with EBNA-1 of Epstein-Barr virus. Virology (1997) 236:18-29. doi:10.1006/viro.1997.8739

28. Mohan KV, Ghebrehiwet B, Atreya CD. The N-terminal conserved domain of rubella virus capsid interacts with the C-terminal region of cellular p32 and overexpression of p32 enhances the viral infectivity. Virus Res (2002) 85:151-61. doi:10.1016/S0168-1702(02)00030-8

29. Kojouharova MS, Gadjeva MG, Tsacheva IG, Zlatarova A, Roumenina LT, Tchorbadjieva MI, et al. Mutational analyses of the recombinant globular regions of human $\mathrm{Clq} A, \mathrm{~B}$, and $\mathrm{C}$ chains suggest an essential role for arginine and histidine residues in the C1q-IgG interaction. J Immunol (2004) 172:4351-8. doi:10.4049/jimmunol.172.7.4351

30. Pednekar L, Pathan AA, Paudyal B, Tsolaki AG, Kaur A, Kouser L, et al. Analysis of the interaction between globular head modules of human $\mathrm{C} 1 \mathrm{q}$ and its receptor gC1qR. Front Immunol (2016) 7:567. doi:10.3389/fimmu.2016.00567

31. Lang SM, Bynoe MO, Karki R, Tartell MA, Means RE. Kaposi's sarcomaassociated herpesvirus $\mathrm{K} 3$ and $\mathrm{K} 5$ proteins down regulate both DC-SIGN and DC-SIGNR. PLoS One (2013) 8:e58056. doi:10.1371/journal.pone. 0058056

32. Kang YS, Do Y, Lee HK, Park SH, Cheong C, Lynch RM, et al. A dominant complement fixation pathway for pneumococcal polysaccharides initiated by SIGN-R1 interacting with C1q. Cell (2006) 125:47-58. doi:10.1016/j. cell.2006.01.046

33. Gadjeva MG, Rouseva MM, Zlatarova AS, Reid KB, Kishore U, Kojouharova MS. Interaction of human $\mathrm{Clq}$ with IgG and IgM: revisited. Biochemistry (2008) 47:13093-102. doi:10.1021/bi801131h

34. Delibrias CC, Fischer EM, Kazatchkine MD. The enhancing role of complement in human immunodeficiency virus infection: soluble recombinant CR1 (CD35) inhibits complement-mediated enhancement of infection of a CD4positive T-cell line with human immunodeficiency virus-1. Scand J Immunol (2000) 51:526-9. doi:10.1046/j.1365-3083.2000.00715.x

35. Bouhlal H, Galon J, Kazatchkine MD, Fridman WH, Sautes-Fridman C, Haeffner Cavaillon N. Soluble CD16 inhibits CR3 (CD11b/CD18)-mediated infection of monocytes/macrophages by opsonized primary R5 HIV-1. J Immunol (2001) 166:3377-83. doi:10.4049/jimmunol.166.5.3377

36. Bouhlal H, Chomont N, Requena M, Nasreddine N, Saidi H, Legoff J, et al. Opsonization of HIV with complement enhances infection of dendritic cells and viral transfer to CD4 T cells in a CR3 and DC-SIGN-dependent manner. J Immunol (2007) 178:1086-95. doi:10.4049/jimmunol.178.2.1086 
37. Tacnet-Delorme P, Boyer V, Thielens NM, Hernandez JF, Bally I, Sim RB, et al. In vitro analysis of complement-dependent HIV-1 cell infection using a model system. J Immunol (1999) 162:4088-93.

38. Delibrias CC, Kazatchkine MD, Fischer E. Evidence for the role of CR1 (CD35), in addition to CR2 (CD21), in facilitating infection of human T cells with opsonized HIV. Scand J Immunol (1993) 38:183-9. doi:10.111 1/j.1365-3083.1993.tb01711.x

39. Banki Z, Wilflingseder D, Ammann CG, Pruenster M, Mullauer B, Hollander $\mathrm{K}$, et al. Factor I-mediated processing of complement fragments on HIV immune complexes targets HIV to CR2-expressing B cells and facilitates B cell-mediated transmission of opsonized HIV to T cells. J Immunol (2006) 177:3469-76. doi:10.4049/jimmunol.177.5.3469

40. Appelmelk BJ, van Die I, van Vliet SJ, Vandenbroucke-Grauls C, Geijtenbeek TB, van Kooyk Y. Cutting edge: carbohydrate profiling identifies new pathogens that interact with dendritic cell-specific ICAM-3-grabbing nonintegrin on dendritic cells. J Immunol (2003) 170:1635-9. doi:10.4049/ jimmunol.170.4.1635

41. Geijtenbeek TB, Krooshoop DJ, Bleijs DA, van Vliet SJ, van Duijnhoven GC, Grabovsky V, et al. DC-SIGN-ICAM-2 interaction mediates dendritic cell trafficking. Nat Immunol (2000) 1:353-7. doi:10.1038/79815

42. McLachlan AD, Stewart M. Tropomyosin coiled-coil interactions: evidence for an unstaggered structure. J Mol Biol (1975) 98:293-304. doi:10.1016/ S0022-2836(75)80119-7

43. Gaboriaud C, Juanhuix J, Gruez A, Lacroix M, Darnault C, Pignol D, et al. The crystal structure of the globular head of complement protein $\mathrm{Clq}$ provides a basis for its versatile recognition properties. J Biol Chem (2003) 278:46974-82. doi:10.1074/jbc.M307764200

44. Roumenina LT, Ruseva MM, Zlatarova A, Ghai R, Kolev M, Olova N, et al. Interaction of $\mathrm{Clq}$ with $\operatorname{IgG1}$, C-reactive protein and pentraxin 3: mutational studies using recombinant globular head modules of human C1q A, B, and C chains. Biochemistry (2006) 45:4093-104. doi:10.1021/bi052646f

45. Gadjeva M, Zlatarova A, Ruseva M, Kishore U, Kojouharova M. Mutational analysis of ligand-binding activities of recombinant gC1q heterotrimer. $\mathrm{Mol}$ Immunol (2010) 47:2260-2260. doi:10.1016/j.molimm.2010.05.188

46. Burton DR, Boyd J, Brampton AD, Easterbrook-Smith S, Emanuel EJ, Novotny J, et al. The Clq receptor site on immunoglobulin G. Nature (1980) 288:338-44. doi:10.1038/288338a0

47. Balzarini J, Van Damme L. Microbicide drug candidates to prevent HIV infection. Lancet (2007) 369:787-97. doi:10.1016/S0140-6736(07)60202-5

48. Balzarini J, Van Laethem K, Daelemans D, Hatse S, Bugatti A, Rusnati M, et al. Pradimicin A, a carbohydrate-binding nonpeptidic lead compound for treatment of infections with viruses with highly glycosylated envelopes, such as human immunodeficiency virus. J Virol (2007) 81:362-73. doi:10.1128/ JVI.01404-06

49. Hoorelbeke B, Xue J, LiWang PJ, Balzarini J. Role of the carbohydrate-binding sites of griffithsin in the prevention of DC-SIGN-mediated capture and transmission of HIV-1. PLoS One (2013) 8:e64132. doi:10.1371/journal. pone.0064132

50. Bashirova AA, Geijtenbeek TB, van Duijnhoven GC, van Vliet SJ, Eilering JB, Martin MP, et al. A dendritic cell-specific intercellular adhesion molecule 3-grabbing nonintegrin (DC-SIGN)-related protein is highly expressed on human liver sinusoidal endothelial cells and promotes HIV-1 infection. J Exp Med (2001) 193:671-8. doi:10.1084/jem.193.6.671

51. Kang YS, Yamazaki S, Iyoda T, Pack M, Bruening SA, Kim JY, et al. SIGN-R1, a novel C-type lectin expressed by marginal zone macrophages in spleen, mediates uptake of the polysaccharide dextran. Int Immunol (2003) 15:177-86. doi:10.1093/intimm/dxg019

52. Leavy O. Innate immunity: a new way to get complement. Nat Rev Immunol (2006) 4:490-1.

53. Prabagar MG, Do Y, Ryu S, Park JY, Choi HJ, Choi WS, et al. SIGN-R1, a C-type lectin, enhances apoptotic cell clearance through the complement deposition pathway by interacting with $\mathrm{Clq}$ in the spleen. Cell Death Differ (2013) 20:535-45. doi:10.1038/cdd.2012.160

54. Solder BM, Schulz TF, Hengster P, Lower J, Larcher C, Bitterlich G, et al. HIV and HIV-infected cells differentially activate the human complement system independent of antibody. Immunol Lett (1989) 22:135-45. doi:10.1016/0165-2478(89)90180-6

55. Banapour B, Sernatinger J, Levy JA. The AIDS-associated retrovirus is not sensitive to lysis or inactivation by human serum. Virology (1986) 152:268-71. doi:10.1016/0042-6822(86)90392-2

56. Gras GS, Dormont D. Antibody-dependent and antibody-independent complement-mediated enhancement of human immunodeficiency virus type 1 infection in a human, Epstein-Barr virus-transformed B-lymphocytic cell line. J Virol (1991) 65:541-5.

57. Boyer V, Desgranges C, Trabaud MA, Fischer E, Kazatchkine MD. Complement mediates human immunodeficiency virus type 1 infection of a human $\mathrm{T}$ cell line in a CD4-and antibody-independent fashion. J Exp Med (1991) 173:1151-8. doi:10.1084/jem.173.5.1151

58. Nayak A, Ferluga J, Tsolaki AG, Kishore U. The non-classical functions of the classical complement pathway recognition subcomponent C1q. Immunol Lett (2010) 131:139-50. doi:10.1016/j.imlet.2010.03.012

59. Nayak A, Pednekar L, Reid KB, Kishore U. Complement and non-complement activating functions of C1q: a prototypical innate immune molecule. Innate Immun (2012) 18:350-63. doi:10.1177/1753425910396252

60. Vegh Z, Kew RR, Gruber BL, Ghebrehiwet B. Chemotaxis of human monocyte-derived dendritic cells to complement component $\mathrm{C} 1 \mathrm{q}$ is mediated by the receptors gC1qR and cC1qR. Mol Immunol (2006) 43:1402-7. doi:10.1016/j. molimm.2005.07.030

61. Ghebrehiwet B, Lim BL, Kumar R, Feng X, Peerschke EI. gC1q-R/p33, a member of a new class of multifunctional and multicompartmental cellular proteins, is involved in inflammation and infection. Immunol Rev (2001) 180:65-77. doi:10.1034/j.1600-065X.2001.1800106.x

62. Ghebrehiwet B, Jesty J, Xu S, Vinayagasundaram R, Vinayagasundaram U, Ji $\mathrm{Y}$, et al. Structure-function studies using deletion mutants identify domains of $\mathrm{gClqR} / \mathrm{p} 33$ as potential therapeutic targets for vascular permeability and inflammation. Front Immunol (2011) 2:58. doi:10.3389/fimmu.2011. 00058

Conflict of Interest Statement: The authors declare that the research was conducted in the absence of any commercial or financial relationships that could be construed as a potential conflict of interest.

Copyright (C) 2016Pednekar, Pandit, Paudyal, Kaur, Al-Mozaini, Kouser, Ghebrehiwet, Mitchell, Madan and Kishore. This is an open-access article distributed under the terms of the Creative Commons Attribution License (CC BY). The use, distribution or reproduction in other forums is permitted, provided the original author(s) or licensor are credited and that the original publication in this journal is cited, in accordance with accepted academic practice. No use, distribution or reproduction is permitted which does not comply with these terms. 